\title{
PET/CT and PET/MRI in ophthalmic oncology (Review)
}

\author{
MARIA S. KALEMAKI ${ }^{1}$, APOSTOLOS H. KARANTANAS ${ }^{2,3}$, DIMITRIS EXARCHOS ${ }^{4}$, \\ EFSTATHIOS T. DETORAKIS ${ }^{5}$, ODYSSEAS ZORAS ${ }^{6}$, KOSTAS MARIAS $^{3}$, CORINA MILLO $^{7}$, \\ ULAS BAGCI $^{8}$, IOANNIS PALLIKARIS ${ }^{5}$, ANDREAS STRATIS ${ }^{3}$, IOANNIS KARATZANIS ${ }^{3}$, \\ KOSTAS PERISINAKIS ${ }^{9}$, PAVLOS KOUTENTAKIS ${ }^{1}$, GEORGIOS A. KONTADAKIS ${ }^{5}$, \\ DEMETRIOS A. SPANDIDOS ${ }^{10}$, ARISTIDIS TSATSAKIS ${ }^{11}$ and GEORGIOS Z. PAPADAKIS ${ }^{2,3}$
}

\begin{abstract}
${ }^{1}$ Department of Ophthalmology, Venizeleio General Hospital of Heraklion, 71409 Heraklion; ${ }^{2}$ Department of Radiology, Medical School, University of Crete, 71003 Heraklion; ${ }^{3}$ Foundation for Research and Technology Hellas (FORTH), Computational Biomedicine Laboratory (CBML), 70013 Heraklion; ${ }^{4}$ Department of CT-MRI and PET/CT, Evangelismos Hospital, 10676 Athens; Departments of ${ }^{5}$ Ophthalmology and ${ }^{6}$ Surgical Oncology, Medical School, University of Crete, 71003 Heraklion,

Greece; ${ }^{7}$ Positron Emission Tomography Department, Clinical Center (CC), National Institutes of Health (NIH), Bethesda, MD 20814; ${ }^{8}$ Center for Research in Computer Vision (CRCV), University of Central Florida (UCF), Orlando, FL 32816, USA; ${ }^{9}$ Department of Medical Physics; ${ }^{10}$ Laboratory of Clinical Virology, and ${ }^{11}$ Laboratory of Forensic Sciences and Toxicology, Medical School, University of Crete, 71003 Heraklion, Greece
\end{abstract}

Received November 21, 2019; Accepted December 31, 2019

DOI: 10.3892/ijo.2020.4955

\begin{abstract}
Orbital and ocular anatomy is quite complex consisting of several tissues, which can give rise to both benign and malignant tumors, while several primary neoplasms can metastasize to the orbital and ocular space. Early detection, accurate staging and re-staging, efficient monitoring of treat-
\end{abstract}

Correspondence to: $\mathrm{Dr}$ Georgios Z. Papadakis, Foundation for Research and Technology Hellas (FORTH), Computational Biomedicine Laboratory (CBML), N. Plastira 100, Vassilika Vouton, 70013 Heraklion, Greece

E-mail: gzpapadakis@gmail.com

Abbreviations: EFS, event-free survival; OS, overall survival; AJCC, American Joint Cancer Committee; SUVmax, maximum standardized uptake value; OL, orbital lymphoma; OAL, ocular adnexal lymphoma; NHL, non-Hodgkin's lymphoma; HL, Hodgkin's lymphoma; UM, uveal melanoma; RB, retinoblastoma; CM, conjunctival melanoma; IOP, inflammatory orbital pseudotumor; ${ }^{18}$ F-FDG, ${ }^{18}$ fluoride-fludeoxyglucose; GLUT-1, glucose transporter-1; LN, lymph node; US, ultrasonography; PET, positron emission tomography; CT, computed tomography; PET/CT, positron emission tomography/computed tomography; MRI, magnetic resonance imaging; TNM, tumor-node-metastases, LFTs, liver function tests; PPV, positive predictive value; NPV, negative predictive value; HNSCC, head and neck squamous cell carcinoma; ONG, optic nerve glioma; OPG, optic pathway glioma; NF-1, neurofibromatosis type 1; CRVO, central retinal vein occlusion; ${ }^{18} \mathrm{~F}-\mathrm{FCH},{ }^{18} \mathrm{~F}$-fluorocholine; ${ }^{11} \mathrm{C}$-MET, ${ }^{11} \mathrm{C}$-methionine; FD, fibrous dysplasia; MAS, McCune-Albright syndrome; SSTRs, somatostatin receptors

Key words: orbital tumors, ocular tumors, positron emission tomography/computed tomography, positron emission tomography/ magnetic resonance imaging, cancer, staging ment response, non-invasive differentiation between benign and malignant lesions, and accurate planning of external radiation treatment, are of utmost importance for the optimal and individualized management of ophthalmic oncology patients. Addressing these challenges requires the employment of several diagnostic imaging techniques, such as high-definition digital fundus photography, ultrasound imaging, optical coherence tomography,optical coherence tomography (OCT)-angiography, computed tomography (CT) and magnetic resonance imaging (MRI). In recent years, technological advances have enabled the development of hybrid positron emission tomography (PET)/CT and PET/MRI systems, setting new standards in cancer diagnosis and treatment. The capability of simultaneously targeting several cancer-related biochemical procedures using positron emitting-radiopharmaceuticals, while morphologically characterizing lesions by CT or MRI, together with the intrinsic quantitative capabilities of PET-imaging, provide incremental diagnostic information, enabling accurate, highly efficient and personalized treatment strategies. Aim of the current review is to discuss the current applications of hybrid PET/CT and PET/MRI imaging in the management of patients presenting with the most commonly encountered orbital and ocular tumors.

\section{Contents}

1. Introduction

2. Orbital lymphoma and ocular adnexal lymphoma

3. Uveal melanoma

4. Retinoblastoma

5. Conjunctival melanoma

6. Sebaceous carcinoma

7. Squamous cell carcinoma 

8. Rhabdomyosarcoma
9. Optic nerve glioma
10. Ocular and orbital metastases
11. Inflammatory orbital pseudotumor
12. Fibrous dysplasia
13. PET/MRI
14. Conclusions

\section{Introduction}

The orbital and ocular space consists of several anatomical structures (Fig. 1) out of which various tumors may arise, while orbital or ocular metastases from several primary malignancies can be encountered, often being the first sign of cancer dissemination. Prompt diagnosis, accurate staging and restaging, and effective assessment of treatment response are crucial for designing patient-tailored therapeutic strategies. Cross-sectional imaging with conventional modalities [computed tomography (CT) and magnetic resonance imaging (MRI)] has being widely used for the management of these lesions. However, in recent years, with the emergence of advanced hybrid imaging techniques using positron emission tomography (PET)/CT and PET/MRI systems, as the corner-stone of diagnostic imaging for oncologic purposes, an emerging role of these modalities has been recorded in the management of patients with orbital and ocular tumors. This review focuses on current applications and future directions of PET/CT and PET/MRI in ophthalmic oncology.

PET is a diagnostic imaging technique that enables targeting, visualization and quantification of biochemical processes at the cellular and sub-cellular level, via the three-dimensional (3-D) reconstruction of the bio-distribution of several molecules radiolabeled with positron-emitting isotopes. Hybrid PET/CT systems combine the functional information provided by the PET component with the structural information obtained from CT, enabling attenuation correction of PET-images, accurate anatomic localization of the distribution of the PET-tracer and morphological characterization of lesions, leading to increased diagnostic performance (1). Moreover, the employment of contrast-enhanced CT as part of PET/CT studies, can provide additional diagnostic information, further improving the diagnostic capabilities of the modality (2).

Hybrid PET/MRI systems hold promise for superior diagnostic capabilities for oncologic applications, since MRI is an ionizing-radiation free method, that can be used for the MR-based attenuation correction of the PET-images, while offering superior soft-tissue contrast resolution, together with a broad spectrum of imaging applications such as dynamic contrast enhanced MRI (DCE-MRI), MR-spectroscopy (MRS) and diffusion weighted imaging (DWI), enabling the acquisition of both anatomical and functional information (3). In recent years, technological advancements have led to the development of clinical simultaneous PET/MRI systems, allowing superior spatial registration of PET and MR images and enabling temporal correlation between PET and MRI data, opening a broad new horizon of diagnostic capabilities (4).

The PET-radiopharmaceuticals discussed in the current review are summarized in Table I. ${ }^{18}$ Fluoride-fludeoxyglucose $\left({ }^{18} \mathrm{~F}-\mathrm{FDG}\right)$ is a glucose analogue radiolabeled with fluorine-18 $\left({ }^{18} \mathrm{~F}\right)$, reflecting glucose consumption and therefore, whole-body ${ }^{18}$ FDG PET/CT studies can produce a whole-body metabolic map of the patient (5). Increased glucose uptake is one of the major metabolic features encountered in cancer cells, making ${ }^{18} \mathrm{~F}$-FDG the most widely employed PET-tracer for oncologic purposes $(1,6-8)$. However, abnormally increased ${ }^{18} \mathrm{~F}-\mathrm{FDG}$ activity is not cancer-specific, since various benign processes, such as adenomas, or infectious and inflammatory lesions exhibit hyper-metabolism (9-13). ${ }^{18} \mathrm{~F}$-sodium fluoride $\left({ }^{18} \mathrm{~F}-\mathrm{NaF}\right)$ is a bone seeking PET-radiopharmaceutical, which can effectively target both osteoblastic and osteolytic processes, leading to increased bone surface area being exposed to the blood flow (14). The favorable ${ }^{18} \mathrm{~F}-\mathrm{NaF}$ pharmacokinetics, the superior spatial resolution of PET, together with the inherent quantitative capabilities of PET-imaging and the capability for morphologic characterization of lesions by the CT, render ${ }^{18} \mathrm{~F}-\mathrm{NaF}$ PET/CT a powerful diagnostic tool for oncologic skeletal imaging (15-18). ${ }^{68} \mathrm{Ga}$-DOTA-compounds are somatostatin (SST) analogs, radiolabeled with the positron emitting isotope gallium-68 $\left({ }^{68} \mathrm{Ga}\right)$ through the chelator 1,4,7,10-tetraazacyclododecane-1, 4,7,10-tetraacetic acid (DOTA) (18). The employment of these compounds enables highly efficient targeting of lesions which are characterized by cell-surface over-expression of SST receptors (SSTRs), such as neuroendocrine tumors (NETs), for which PET/CT imaging with ${ }^{68} \mathrm{Ga}$-DOTA-compounds is evolving as the imaging standard of reference (19-33).

\section{Orbital lymphoma and ocular adnexal lymphoma}

Orbital lymphoma (OL) and ocular adnexal lymphoma (OAL), are lypmphoproliferative malignancies, involving the orbit, the eyelid, the conjunctiva, the lacrimal gland, or a combination of these structures (34). OL is the most common primary malignant tumor of the orbits among adults (35), whereas OAL accounts for $55 \%$ of orbital malignancies among adults and represents $1-2 \%$ of non-Hodgkin's lymphoma (NHL) cases and $8 \%$ of extra-nodal mucosa-associated lymphoid tissue (MALT) lymphomas $(36,37)$. In the majority of cases, OALs mainly arise from the lacrimal gland and the conjunctiva, with $7-24 \%$ of patients presenting with bilateral involvement (36). OL and OAL can either be primary malignancies or metastases from systemic disease. Histologically, the most common type of OAL is MALT lymphoma, which is a low-grade B-cell NHL (35). Once the diagnosis of OL or OAL has been established, accurate disease staging is of utmost importance for optimal patient management. Whole-body PET/CT post ${ }^{18} \mathrm{~F}-\mathrm{FDG}$ administration has evolved as the standard of care for initial disease staging and post-treatment evaluation, rendering OL and OAL the main orbital and ocular tumors, for which PET/CT is routinely employed (35) (Figs. 2-4). Low-grade MALT lymphomas may exhibit low hyper-metabolic activity and therefore low-level ${ }^{18} \mathrm{~F}$-FDG uptake, or may even present false negative findings on ${ }^{18} \mathrm{~F}$-FDG PET/CT. However, even for low-grade OLs and OALs, ${ }^{18} \mathrm{~F}-\mathrm{FDG}$ PET/CT has been proven to be highly sensitive for accurate disease staging by detecting distant metastases, missed on conventional imaging $(35,36)$.

In a retrospective study of 11 patients with an established diagnosis of OAL who underwent whole-body ${ }^{18} \mathrm{~F}$-FDG PET scans at initial staging, Valenzuela et al reported that ${ }^{18} \mathrm{~F}-\mathrm{FDG}$ PET exhibited higher sensitivity in detecting systematic 
Table I. PET-radiopharmaceuticals employed for PET/CT studies in patients with orbital and ocular tumors.

\begin{tabular}{|c|c|c|c|c|c|c|}
\hline Feature & ${ }^{18} \mathrm{~F}-\mathrm{FDG}$ & ${ }^{18} \mathrm{~F}-\mathrm{NaF}$ & $\begin{array}{l}{ }^{68} \mathrm{Ga} \text {-DOTA- } \\
\text { compounds }\end{array}$ & $\begin{array}{c}{ }^{18} \mathrm{~F} \text {-fluorocholine } \\
\left({ }^{18} \mathrm{~F}-\mathrm{FCH}\right)\end{array}$ & $\begin{array}{c}{ }^{11} \mathrm{C} \text {-methionine } \\
\left({ }^{11} \mathrm{C}-\mathrm{MET}\right)\end{array}$ & $\begin{array}{c}\text { Alpha- }\left[{ }^{11} \mathrm{C}\right] \\
\text { Methyl-L-Tryptophan } \\
\left({ }^{11} \mathrm{C}-\mathrm{AMT}\right)\end{array}$ \\
\hline Half-life & $110 \mathrm{~min}$ & $110 \mathrm{~min}$ & $68 \min$ & $110 \min$ & $20 \mathrm{~min}$ & $20 \mathrm{~min}$ \\
\hline $\begin{array}{l}\text { Synthesis } \\
\text { requirements }\end{array}$ & Cyclotron & Cyclotron & $\begin{array}{l}\text { In-house } \\
\text { generator }\end{array}$ & Cyclotron & Cyclotron & Cyclotron \\
\hline Molecular target & $\begin{array}{l}\text { Metabolic } \\
\text { activity }\end{array}$ & $\begin{array}{l}\text { Bone } \\
\text { remodeling }\end{array}$ & $\begin{array}{l}\text { SSTRs } \\
\text { cell surface } \\
\text { overexpression }\end{array}$ & $\begin{array}{l}\text { Cell membrane } \\
\text { synthesis }\end{array}$ & $\begin{array}{l}\text { Amino acid } \\
\text { transport }\end{array}$ & $\begin{array}{l}\text { Tryptophan } \\
\text { metabolism }\end{array}$ \\
\hline $\begin{array}{l}\text { Orbital or ocular } \\
\text { tumor }\end{array}$ & $\begin{array}{l}\text { Lymphoma, } \\
\text { uveal melanoma, } \\
\text { retinoblastoma } \\
\text { conjunctival } \\
\text { melanoma, } \\
\text { sebaceous } \\
\text { carcinoma, } \\
\text { squamous cell } \\
\text { carcinoma, optic } \\
\text { nerve glioma, } \\
\text { ocular and orbital } \\
\text { metastases, } \\
\text { inflammatory } \\
\text { orbital } \\
\text { pseudotumor, } \\
\text { fibrous dysplasia }\end{array}$ & $\begin{array}{l}\text { Fibrous } \\
\text { dysplasia }\end{array}$ & $\begin{array}{l}\text { Ocular and orbital } \\
\text { metastases from } \\
\text { neuroendocrine } \\
\text { tumors (NETs) }\end{array}$ & $\begin{array}{l}\text { Optic nerve } \\
\text { glioma }\end{array}$ & & \\
\hline
\end{tabular}

SSTR, somatostatin receptor; ${ }^{18} \mathrm{~F}-\mathrm{FDG},{ }^{18}$ fluoride-fludeoxyglucose; ${ }^{18} \mathrm{~F}-\mathrm{NaF},{ }^{18} \mathrm{~F}$-sodium fluoride.

A

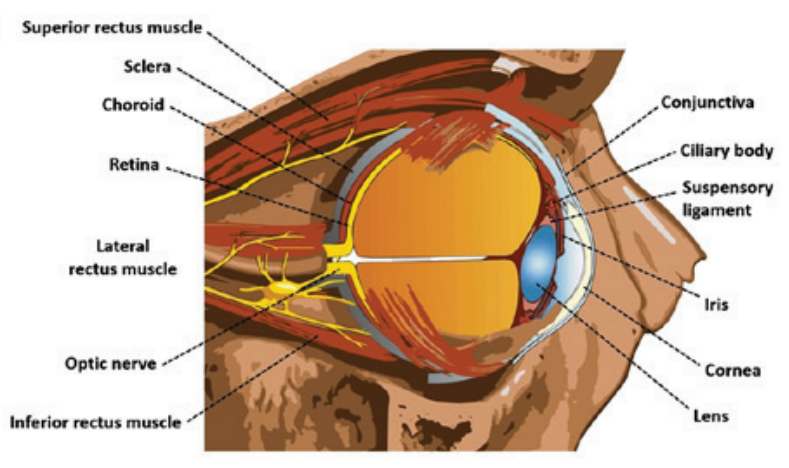

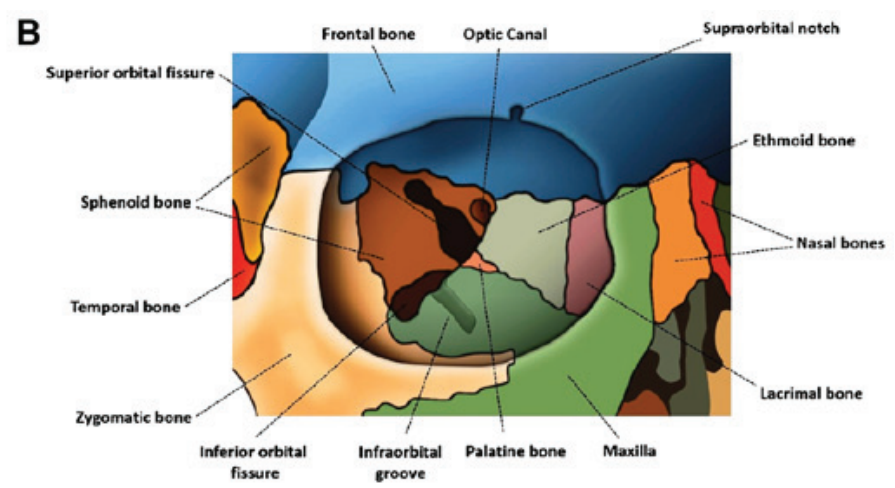

Figure 1. Diagram illustrating (A) the anatomy of the globe and (B) the bone structures forming the orbit.

extra-nodal disease compared to conventional imaging with CT, leading to disease upstaging and significantly affecting patient management; however, the efficacy of the modality in detecting orbital lesions was limited, mainly due to the small size of the lesions and physiologic ${ }^{18} \mathrm{~F}-\mathrm{FDG}$ uptake by the extraocular muscles (38). English and Sullivan, in a series of 34 patients who also underwent ${ }^{18}$ F-FDG PET at initial staging, confirmed the enhanced performance of the modality in accurate disease staging, by detecting sites of systemic disease missed on CT, and therefore, significantly altering management strategies; their study also confirmed the limited performance of ${ }^{18} \mathrm{~F}-\mathrm{FDG}$ PET in comparison to CT in detecting local OAL lesions (37).
However, the advent of hybrid PET/CT technology had a direct impact on OL and OAL detection performance. Roe et al, in a series of 4 patients with biopsy-proven OAL, demonstrated that hybrid ${ }^{18} \mathrm{~F}-\mathrm{FDG}$ PET/CT was capable of detecting the orbital tumor in 3 patients (75\%), while revealing systematic involvement in 2 of the 4 patients (50\%) (39). Suga et al reported that in a patient with orbital MALT lymphoma, ${ }^{18}$ F-FDG PET/CT was able to identify a small lesion in the contralateral orbit, which had been missed on MR-imaging, and an unexpected metastatic gastric lesion, indicating the increased efficacy of the method in accurate disease staging (40). Furthermore, post-treatment ${ }^{18} \mathrm{~F}-\mathrm{FDG} \mathrm{PET} / \mathrm{CT}$ scans revealed progressive regression and 


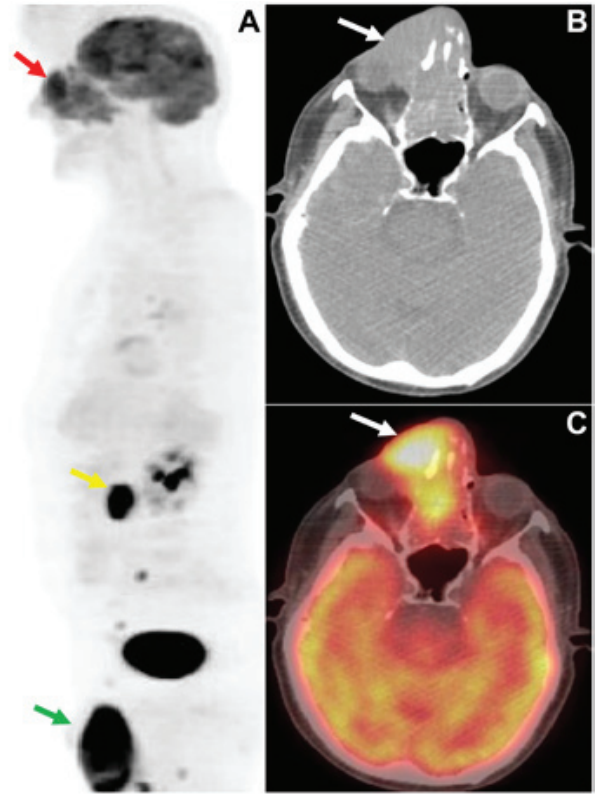

Figure 2. A 68-year-old male patient who presented with swelling, ptosis and a right orbital/sinonasal mass. (A) Sagittal view of the maximum intensity projection (MIP) ${ }^{18} \mathrm{~F}$-FDG PET image of the head and the torso showing (red arrow) intensely elevated activity (SUVmax:13) by the orbital/sinonasal mass and hypermetabolic lesions in para-aortic lymph nodes (yellow arrow) and in the testes (green arrow), indicating metastatic dissemination, and enabling accurate disease staging. (B and C) Axial CT and fused ${ }^{18} \mathrm{~F}$-FDG $\mathrm{PET} / \mathrm{CT}$ images of the skull illustrating the hypermetabolic orbital/sinonasal mass infiltrating the right orbit. Histology revealed B-cell non-Hodgkin's lymphoma. SUVmax, maximum standardized uptake value; ${ }^{18} \mathrm{~F}$-FDG, ${ }^{18} \mathrm{flu}-$ oride-fludeoxyglucose; PET/CT, positron emission tomography/computed tomography.

finally the disappearance of ${ }^{18} \mathrm{~F}$-FDG activity at disease sites, suggesting the utility of the modality for monitoring treatment response (40). Several other studies have confirmed the usefulness of ${ }^{18} \mathrm{~F}$-FDG PET/CT for the initial staging and assessment of treatment response in patients with OLs and OALs (41-43).

Fuji et al, in a recent series of 9 patients with histologically proven OAL [diffuse large B-cell lymphoma, MALT, follicular lymphoma, natural killer (NK)/T-cell lymphoma, lymphoplasmacytic lymphoma, Hodgkin's lymphoma (HL)] who underwent pre- and post- treatment ${ }^{18} \mathrm{~F}$-FDG PET/CT investigated the utility of the modality in assessing treatment response (44). ${ }^{18} \mathrm{~F}-\mathrm{FDG}$ uptake was assessed by means of maximum standardized uptake value (SUVmax), and a decrease was recorded in 8 out of the 9 patients post-treatment, while in 7 patients there was a complete metabolic response from the first post-treatment scan, which was in accordance with the clinical condition of the patients during the follow-up period. Only in one patient there was a false-negative conjunctival lesion on ${ }^{18} \mathrm{~F}-\mathrm{FDG}$ PET/CT, indicating that the usefulness of the modality may be affected by the histological type and the anatomic location.

\section{Uveal melanoma}

Uveal melanoma (UM) (Fig. 5) is the most common primary intraocular malignancy among adults, and most frequently arises from the choroid (85\% of cases) $(36,45)$. Singh et al, in a systematic review including 4,070 patients with primary UM in the USA over a 36-year period from 1973 to 2008,
A
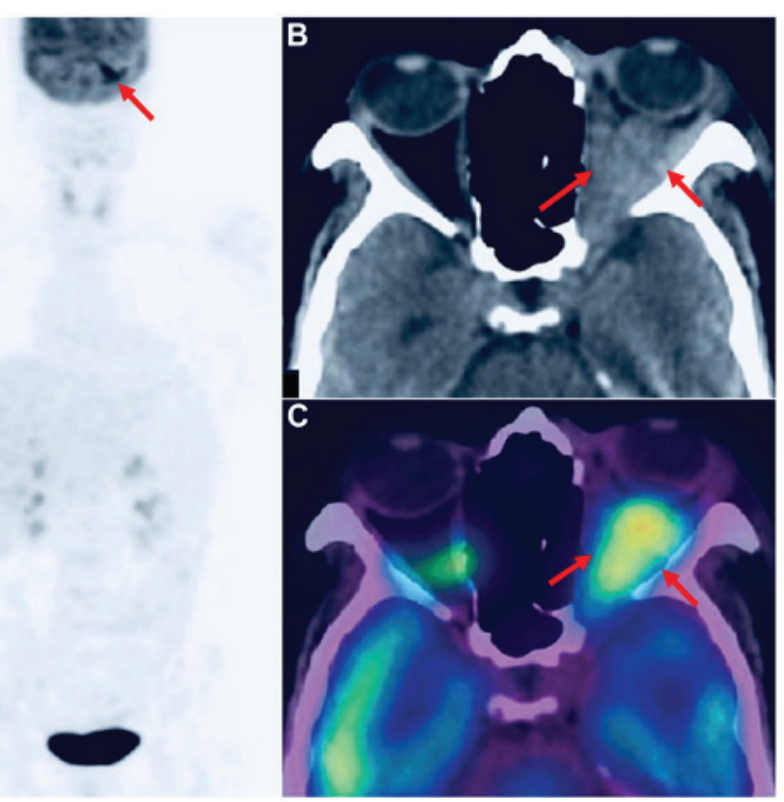

Figure 3. A 62-year-old male patient who presented with exophthalmos and abnormal ocular movement. (A) Maximum intensity projection (MIP) ${ }^{18} \mathrm{~F}-\mathrm{FDG}$ PET image of the head and the torso showing (red arrow) abnormally increased (SUVmax: 9) 18F-FDG uptake in the left orbit. (B and C) Axial CT and fused ${ }^{18} \mathrm{~F}-\mathrm{FDG}$ PET/CT images of the skull showing (red arrows) the hypermetabolic retro-orbital mass. Histology revealed left B-cell NHL MALT lymphoma. Whole-body ${ }^{18} \mathrm{~F}$-FDG PET/CT contributed to accurate patient management by excluding distant metastatic lesions. SUVmax, maximum standardized uptake value; ${ }^{18} \mathrm{~F}$-FDG,${ }^{18}$ fluoride-fludeoxyglucose; PET/CT, positron emission tomography/computed tomography; NHL, non-Hodgkin's lymphoma; MALT, mucosa-associated lymphoid tissue.

reported a mean age-adjusted incidence of 5.1 per million of population (95\% CI, 4.8-5.3), a predilection for the Caucasian population (97.8\% of cases) and an unaltered 5-year survival rate of $81.6 \%$ (46). Tumor size, an age $>60$ years, intense tumor pigmentation and localization in the anterior uvea have been shown to indicate a poor prognosis (36). Although distant metastases can occur to the lungs, bones and the central nervous system, UM presents a unique metastatic pattern to the liver, as the main site for disease dissemination $(36,45,47)$. Therefore, accurate disease staging is critical for guiding decision-making in patients diagnosed with UM.

In an early study by Reddy et al, including a cohort of 50 patients with untreated choroidal melanomas [American Joint Cancer Committee (AJCC); T1:18 patients, 36\%; T2:24 patients, 48\%; T3:8 patients, $16 \%],{ }^{18} \mathrm{~F}-\mathrm{FDG}$ PET/CT failed to detect any of the AJCC-T1 tumors, while increased ${ }^{18}$ F-FDG activity (SUVmax $>2.5$ ) was observed in 33 and $75 \%$ of AJCC-T2 and AJCC-T3 choroidal melanomas, respectively (48). According to these findings, it was suggested that ${ }^{18}$ F-FDG PET/CT most likely cannot differentiate small UMs from suspicious nevi, and does not seem to be superior over standard clinical evaluation with ophthalmoscopy, fluorescein angiography and ophthalmic ultrasonography (US) in the detection of primary choroidal melanomas. Finger et al, in a series of 14 patients with choroidal melanomas (AJCC-T2, 1 patient; AJCC-T3, 13 patients), reported that the one T2 tumor and 10 out of the $13(77 \%)$ T3 tumors demonstrated elevated ${ }^{18}$ F-FDG uptake (SUVmax $>2.5$ ) with the highest SUV value 

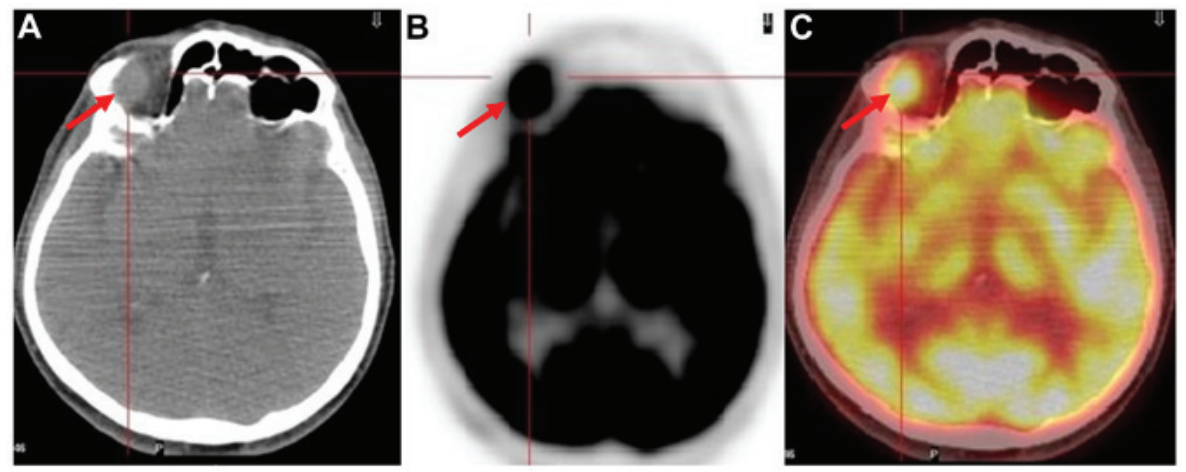

Figure 4. A 72-year-old male patient with a history of tonsil non-Hodgkin's lymphoma who presented with enlargement of the inguinal lymph nodes bilaterally. A follow-up whole-body ${ }^{18}$ F-FDG PET/CT study revealed a hypermetabolic (SUVmax:11) right ocular mass, which did not produce any symptoms. (A) Axial CT image of the skull revealed (red arrow) the mass. (B and C) Axial ${ }^{18} \mathrm{~F}-\mathrm{FDG}$ PET and fused ${ }^{18} \mathrm{~F}-\mathrm{FDG}$ PET/CT images of the skull, illustrating (red arrows) the ocular site with abnormally increased radiotracer uptake. SUVmax, maximum standardized uptake value; ${ }^{18} \mathrm{~F}-\mathrm{FDG},{ }^{18}$ fluoride-fludeoxyglucose; PET/CT, positron emission tomography/computed tomography.

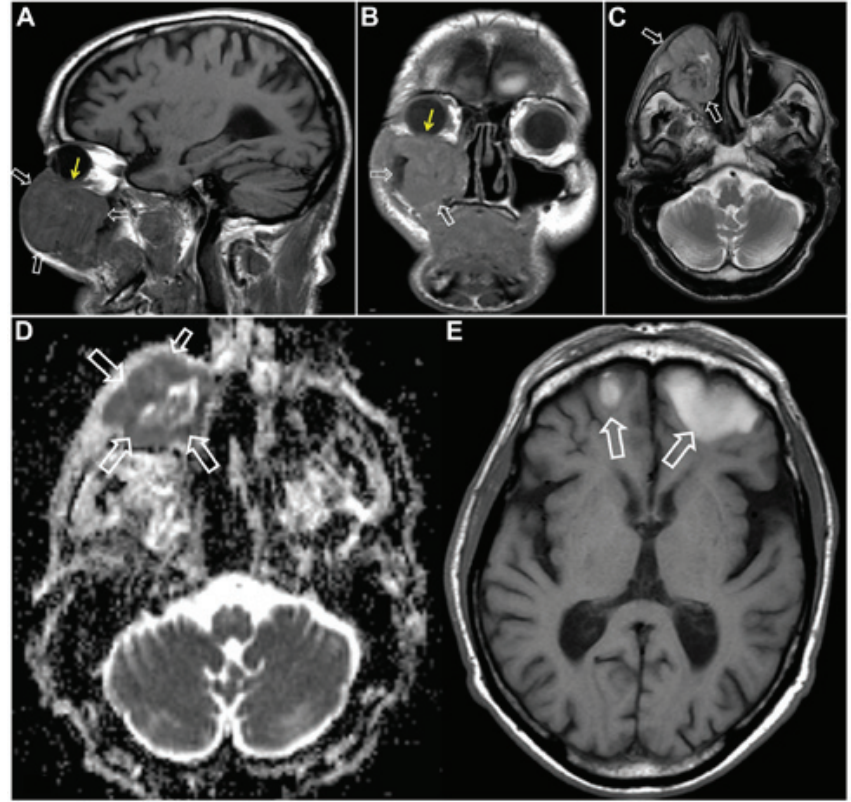

Figure 5. MR imaging in recurrent uveal melanoma in a 65-year-old male patient with a history of melanoma 3 years prior to imaging. Patient presented with swelling of the right infraorbital area and behavioral changes. (A-C) Sagittal T1-w (A), coronal T1-w (B) and axial T2-w (C) images, respectively, showing the origin of the recurrent tumor from the lower uvea (thin yellow arrows) and the extraconal extension within and anterior to the right maxillary sinus (open white arrows). (D) Apparent diffusion coefficient (ADC) map showing (open white arrows) restricted diffusion consistent with an aggressive lesion. (E) Axial T1-w MR image showing (open white arrows) hyperintensity, due to hemorrhage or melanin formation, metastatic brain lesions in the frontal lobes.

(9.0) observed in the tumor which was largest in size (49). Furthermore, they reported a positive association between SUV values with known clinical, pathological and US characteristics related to increased metastatic potential, indicating possible prognostic value of ${ }^{18}$ F-FDG uptake observed on PET/CT in the setting of UM (49).

In a cohort of 7 patients with choroidal melanoma, Matsuo et al explored the association between ${ }^{18} \mathrm{~F}$-FDG avidity and the clinicopathological characteristics of the tumors. ${ }^{18} \mathrm{~F}$-FDG PET/CT detected the primary tumor in 5 out of 7 patients, concluding that large nodular choroidal melanomas can be effectively identified by ${ }^{18} \mathrm{~F}-\mathrm{FDG}$ PET/CT, in contrast to diffusely infiltrating choroidal melanomas without nodular formation, which proved to be ${ }^{18} \mathrm{~F}$-FDG-negative (50). However, all distant liver and bony metastases in 2 of the patients in the cohort were effectively targeted with ${ }^{18} \mathrm{~F}-\mathrm{FDG}$ $\mathrm{PET} / \mathrm{CT}$, suggesting the employment of the modality for disease staging. Furthermore, a positive association was reported between tumor size, as defined by histopathological measurements and ${ }^{18} \mathrm{~F}$-FDG uptake, as determined by SUVmax (50). McCannel et al, in a retrospective study including 37 patients with primary choroidal melanomas, reported significant association between ${ }^{18} \mathrm{~F}-\mathrm{FDG}$ positivity of the tumors (SUVmax >2.5) with larger tumor size and with chromosome 3 loss, which is a known risk factor related with increased metastatic potential of choroidal melanomas (51). This data indicated that apart from tumor size, ${ }^{18} \mathrm{~F}-\mathrm{FDG}$ positivity may be associated with molecular features of UMs and that ${ }^{18} \mathrm{~F}-\mathrm{FDG}$ avidity holds promise to serve as an independent prognostic biomarker for patients with UM.

Papastefanou et al, in a retrospective study of 76 patients diagnosed with UM who underwent pre-operative ${ }^{18} \mathrm{~F}-\mathrm{FDG}$ PET/CT scans, reported ${ }^{18}$ F-FDG positivity (SUVmax $>2.5$ ) in $92 \%$ of the tumors (52). In addition, $94 \%$ of patients with chromosome 3 monosomy exhibited ${ }^{18}$ F-FDG avidity (SUVmax >2.5), whereas patients with abnormalities (gains) in chromosome 8 , which is also associated with a poor prognosis in UM did not exhibit significantly higher ${ }^{18} \mathrm{~F}-\mathrm{FDG}$ activity. Moreover, increased tumor size and AJCC tumor-node-metastases (TNM) prognostic groups were positively associated with ${ }^{18}$ F-FDG uptake, as determined by SUVmax, further implying the prognostic application of ${ }^{18} \mathrm{~F}-\mathrm{FDG} \mathrm{PET} / \mathrm{CT}$ imaging in the setting of patients with UM (52).

However, the main indication for the employment of ${ }^{18} \mathrm{~F}-\mathrm{FDG}$ PET/CT in the work-up of patients with UM is the detection of regional and distant metastasis. Kurli et al reported $100 \%$ sensitivity and $100 \%$ specificity of ${ }^{18} \mathrm{~F}$-FDG PET/CT in detecting liver metastases compared to $12.5 \%$ sensitivity of liver function tests (LFTs). Furthermore, ${ }^{18} \mathrm{~F}$-FDG PET/CT significantly contributed to the detection of osseous extra-hepatic metastatic lesions, implying the application of this technique for disease staging at the time of initial diagnosis as well as for follow-up purposes (53). In a large retrospective series of 
333 patients with UM, who underwent whole-body ${ }^{18} \mathrm{~F}-\mathrm{FDG}$ PET/CT studies for staging purposes at the time of initial diagnosis, Freton et al confirmed the value of the modality as a screening tool for initial staging (54). All ${ }^{18} \mathrm{~F}$-FDG-positive liver lesions observed on PET/CT were subsequently confirmed as metastases via biopsies, indicating $100 \%$ positive predictive value (PPV), providing significant advantages over anatomic imaging techniques, which exhibit a higher rate of false-positive liver findings. Furthermore, ${ }^{18} \mathrm{~F}-\mathrm{FDG}$ PET/CT enabled the detection of extra-hepatic disease sites missed on blood tests or conventional imaging, and revealed synchronous second primary malignancies in $3.3 \%$ (95\% CI: $0.9-5.5)$ of the study population, significantly affecting patient management (54).

However, Strobel et al, in a retrospective study of 13 patients with UM, questioned the usefulness of ${ }^{18} \mathrm{~F}-\mathrm{FDG}$ PET/CT in UM staging, since 16 out of 27 liver lesions (59\%) were ${ }^{18}$ F-FDG-negative, all of which were detected by anatomic imaging with CT or MRI (55). Furthermore, liver metastases from UM demonstrated significantly $(\mathrm{P}<0.001)$ lower ${ }^{18} \mathrm{~F}$-FDG uptake in terms of SUVmax in comparison to liver metastases from cutaneous melanoma, although histological analysis did not reveal any difference in glucose transporter-1 (GLUT-1) expression between UM and CM liver metastases (55). In accordance with the findings of the study by Strobel et al (55), Orcurto et al reported the superiority of MRI over ${ }^{18} \mathrm{~F}$-FDG PET/CT in detecting small metastatic liver lesions in patients with UM (56). However, Orcurto et al (56) observed that during chemotherapy, ${ }^{18} \mathrm{~F}-\mathrm{FDG}$ activity in liver lesions with a stable size on MRI, exhibited a significantly decreased lesion-to-liver SUV ratio, while enlarging lesions on MRI exhibited an increased lesion-to-liver SUV ratio. These data suggest the application of ${ }^{18} \mathrm{~F}-\mathrm{FDG}$ PET/CT in the early assessment of treatment response (56).

\section{Retinoblastoma}

Retinoblastoma $(\mathrm{RB})$ is a malignant tumor of the retina originating from precursor cells of the retinal neuroepithelium (36). $\mathrm{RB}$ is the most common intraocular tumor in childhood, with $95 \%$ of patients being diagnosed by the age of 5 (57). RB can be encountered either in a hereditary $(40 \%)$ or in a sporadic form $(60 \%)$, with patients with hereditary RB presenting with an increased risk of developing intracranial primitive neuroectodermal tumor (PNET), most frequently pineoblastomas (58-60). The combination of unilateral or bilateral hereditary RB with an intracranial PNET is termed trilateral $\mathrm{RB}$, which is often associated with a poor prognosis due to spinal dissemination (61). RBs typically present with leukocoria, while proptosis, pain, redness and swelling can be common RB manifestations (62).

Radhakrishnan et $a l$, in a prospective evaluation of the role of ${ }^{18} \mathrm{~F}-\mathrm{FDG}$ PET/CT in staging and assessment of the response to neoadjuvant chemotherapy, demonstrated that intraocular $\mathrm{RB}$ did not take up the radiotracer, in contrast to the ${ }^{18} \mathrm{~F}-\mathrm{FDG}$ avidity of extraocular RBs (63). Furthermore, no significant difference was revealed between staging with $\mathrm{CT}$ or MRI and staging based on ${ }^{18} \mathrm{~F}$-FDG PET/CT findings. However, the detection of ${ }^{18} \mathrm{~F}$-FDG uptake by the optic nerve at the baseline PET/CT study was strongly associated with poor event-free survival (EFS) and overall survival (OS), indicating a strong prognostic value, in comparison to patients with no ${ }^{18} \mathrm{~F}$-FDG uptake by the optic nerve. In addition, a complete or partial response to neoadjuvant chemotherapy assessed by ${ }^{18} \mathrm{~F}-\mathrm{FDG}$ PET/CT was associated with an improved EFS and OS, further supporting the prognostic value of the modality (63).

\section{Conjunctival melanoma}

Conjunctival melanoma $(\mathrm{CM})$ is a relatively rare, yet potentially lethal malignancy with an increasing incidence rate (64). Folberg et al reported that approximately $75 \%$ of CMs typically arise from primary acquired melanosis (PAM), with 9-25\% of patients with CM presenting local or systematic spread with lymph node $(\mathrm{LN})$ involvement $(65,66)$. In a retrospective cross-sectional study including 85 patients with primary CM, aiming to elucidate the metastatic pattern of this neoplasm, Tuomaala and Kivelä demonstrated that initial regional LN and systematic metastasis were equally encountered, with LN infiltration being associated with a better prognosis (67). Major metastatic sites are the lungs, the liver, the gastrointestinal track and the central nervous system (68).

${ }^{18}$ F-FDG PET/CT has been employed for staging purposes in patients with CM. Kurli et al investigated 14 patients with CM (13 patients with T3 tumors, 1 patient with T4 tumor), who were evaluated with whole body ${ }^{18} \mathrm{~F}-\mathrm{FDG}$ PET/CT scans for the detection of metastatic disease (68). Seven of these patients were scanned with ${ }^{18} \mathrm{~F}-\mathrm{FDG}$ PET/CT at initial diagnosis and 7 were imaged post-treatment (surgical removal with adjuvant cryotherapy and/or chemotherapy). The study concluded that ${ }^{18}$ F-FDG PET/CT failed to reveal local, regional or systemic disease in any of the 13 patients with diffuse, multifocal T3 CM, either at initial diagnosis or post-treatment. On the contrary, the post-treatment ${ }^{18} \mathrm{~F}$-FDG PET/CT scan revealed widespread metastases in the nasal fossa, liver, pleural space, mediastinal lymph nodes, lungs, peritoneal cavity, lumbar spine and right supraclavicular lymph node in the patient with T4 CM. Based on these data, Kurli et al suggested the limited application of ${ }^{18} \mathrm{~F}$-FDG PET/CT at the initial staging of patients with CM, with potential usefulness for follow-up and re-staging purposes (68).

Damian et al reported the positive contribution of ${ }^{18} \mathrm{~F}-\mathrm{FDG}$ $\mathrm{PET} / \mathrm{CT}$ in the effective management of a patient with $\mathrm{CM}$, by successfully detecting the primary ocular lesion and an infiltrated preauricular node, and by excluding other LN involvement or systemic dissemination of the disease (66). Tsai et al described the usefulness of ${ }^{18} \mathrm{~F}-\mathrm{FDG}$ PET/CT in revealing $\mathrm{CM}$ as a second primary neoplasm, in a patient with lymphocytic lymphoma/chronic lymphocytic leukemia (CLL) and nasal cavity carcinoma (69). Given these data, further studies are required to explore the potential usefulness of ${ }^{18} \mathrm{~F}-\mathrm{FDG} \mathrm{PET} / \mathrm{CT}$ in the management of CM.

\section{Sebaceous carcinoma}

Sebaceous carcinoma (SebCa) is a rare type of cancer with a low incidence rate ( 0.11 to 0.65 cases $/ 100,000$ individuals/year) and a higher prevalence in the female population $(70,71)$. With the face being the most common anatomical region for SebCa due to the abundance of sebaceous glands, it is usually presented as a nodule or diffuse thickening of the eyelids (71). Although the upper lid and the palpebral conjunctiva are the most common sites, SebCa may also arise in the bulbar 
conjunctiva and the caruncle (71). Eyelid SebCa can often be misdiagnosed both clinically and pathologically (72). Typically, there is a delay in the diagnosis associated with a higher recurrence rate following surgical excision, ranging from 18 to $19.4 \%$ (71,72). Distant and nodal metastases have been associated with eyelid SebCa in 3-8 and 8-18\% of cases, respectively (71).

In a series of 15 patients with biopsy-proven periorbital tumors Baek et al, reported that in the subset of patients (5 out of 15) with SebCa of the upper eyelid ${ }^{18} \mathrm{~F}-\mathrm{FDG}$ PET/CT successfully detected all cases with regional LN involvement, even when contrast-enhanced CT was falsely negative (73). Krishna et al reported the employment of ${ }^{18} \mathrm{~F}-\mathrm{FDG}$ PET/CT in successfully staging 2 patients with ocular SebCa, critically contributing to optimal patient management, guiding the decision to preserve the eye and implying the application of the modality in accurate staging of ocular and non-ocular SebCas (74). Furthermore, follow-up in patients with SebCa can be facilitated with ${ }^{18} \mathrm{~F}-\mathrm{FDG}$ PET/CT. Ishiguro et al reported the detection of a colon adenocarcinoma 42 months following the surgical removal of a left upper eyelid SebCa, in a patient with Muir-Torre syndrome, which is characterized by the presence of at least one sebaceous skin tumor (75). Thus, ${ }^{18} \mathrm{~F}-\mathrm{FDG} \mathrm{PET} / \mathrm{CT}$ is of value for staging and restaging purposes in patients with $\mathrm{SebCa}$.

\section{Squamous cell carcinoma}

Squamous cell carcinoma (SCC) is a type of skin cancer which manifests as a scaled, indurated, keratinized or ulcerated raised nodule or plaque, which is most commonly encountered in the lower eyelid and medial canthus, with an incidence rate 3 -fold higher in males than in females (71). SCC arises from abnormal keratinocyte proliferation and either emerges for the first time without any previous predisposition or in sites of pre-existing actinic or solar keratosis (71). The clinical presentation of SCC may vary from erythematous patches to large ulcerated lesions. The 5-year recurrence rate ranges from 2.4 to $36.9 \%$ with regional $\mathrm{LN}$ involvement at $25 \%$ of cases, and distant metastases in $6.2 \%$ of cases, with the most common regional metastatic sites being the parotid, the preauricular and the submandibular nodes (76,77). Periocular SCC is highly metastatic in the case of delayed treatment, invading orbital and intracranial structures and leading to considerably increased mortality and morbidity $(78,79)$.

${ }^{18} \mathrm{~F}$-FDG PET/CT has been reported to be an effective tool for the detection of distant metastases in patients with recurrent head and neck SCCs (HNSCCs). In a series of 82 patients with histologically confirmed HNSCCs, Yi et al reported that whole-body ${ }^{18} \mathrm{~F}-\mathrm{FDG}$ PET/CT correctly identified distant metastases in 12 of 14 patients and their absence in 57 of 68 patients, exhibiting sensitivity, specificity, accuracy, PPVs and negative predictive values (NPVs) of $86 \%$ (95\% CI, $57-98 \%), 84 \%(72-91 \%), 84 \%$ (74-91\%), 52\% (30-73\%) and 97\% (88-99\%), respectively (80). Literature on the employment of ${ }^{18} \mathrm{~F}$-FDG PET/CT in the work-up of patients with eyelid or conjunctival SCC is rather limited. Lin et al reported high ${ }^{18}$ F-FDG avidity (SUVmax: 8) by a biopsy proven left bulbar conjunctiva SCC, in a patient with previous history of endometrial lymphoma (81). Abdelmalik et al reported a patient with a biopsy-proven left orbital SCC, which was intensely ${ }^{18} \mathrm{~F}$-FDG avid in the pre-treatment PET/CT scan (82). Furthermore, several retromandibular, mediastinal and abdominal LNs demonstrated increased ${ }^{18} \mathrm{~F}-\mathrm{FDG}$ activity, with only the retromandibular being metastatic and the remainder being inflammatory, highlighting the limitations of the modality in cancer staging, since both malignant and inflammatory processes exhibit elevated ${ }^{18} \mathrm{~F}-\mathrm{FDG}$ uptake (82). Therefore, based on the existing literature, further studies are required to justify the usefulness of ${ }^{18} \mathrm{~F}$-FDG PET/CT in the setting of periocular SCC.

\section{Rhabdomyosarcoma}

Rhabdomyosarcoma (RMS) is the most common mesenchymal tumor in childhood accounting for approximately $4-5 \%$ of all pediatric cancers, with orbits being the commonest site in the head and neck $(36,83)$. Orbital RMS usually presents as a unilateral rapidly progressive mass, leading to proptosis or globe displacement, while eyelid edema, hemorrhage, pain, vision impairment, blepharoptosis, conjunctival edema and inflammatory signs consist non-specific RMS manifestations. RMS of the orbits is an aggressive, life-threatening malignancy with high potential to infiltrate adjacent tissues, while metastatic dissemination can occur to the lungs, bones, bone marrow and LNs (83). Therefore, accurate initial staging and restaging is critical for the optimal and individualized patient management.

Norman et al, in a systematic review including 272 patients with RMS, with orbits being the primary tumor site in at least 13 cases (not all included studies provided information on the location of the primary tumor), investigated the role of ${ }^{18} \mathrm{~F}$-FDG PET and ${ }^{18} \mathrm{~F}$-FDG PET/CT in the management of childhood RMS (84). They reported that ${ }^{18} \mathrm{~F}$-FDG PET and ${ }^{18} \mathrm{~F}-\mathrm{FDG} \mathrm{PET} / \mathrm{CT}$ had been consistently superior over conventional imaging (contrast-enhanced CT, standard MRI, technetium-99m bone scintigraphy) at the initial RMS staging, since $\mathrm{LN}$ involvement and distant metastases were determined with higher accuracy. Furthermore, the management strategy was altered based on ${ }^{18} \mathrm{~F}-\mathrm{FDG}$ PET and ${ }^{18} \mathrm{~F}$-FDG PET/CT findings in 7/40 (17.5\%) RMS patients (not all the included studies provided information on this outcome) (84). However, the role of ${ }^{18} \mathrm{~F}$-FDG PET/CT as a prognostic indicator of the outcome in patients with RMS, is controversial (85). Moreover, patients and particularly pediatric patients with RMS may benefit from ${ }^{18}$ F-FDG PET/MRI, which promises more accurate locoregional staging and follow-up evaluation $(36,86)$.

\section{Optic nerve glioma}

Optic nerve glioma (ONG), also known as optic pathway glioma (OPG), is the most common primary optic nerve tumor, accounting for approximately $1 \%$ of all intracranial tumors. ONG is divided into two types: A low-grade benign form and an aggressive highly malignant form. Benign ONGs are slow-growing tumors, which are mostly encountered in children and are often associated with neurofibromatosis type 1 (NF-1). Bilateral ONGs are almost pathognomonic for NF-1. ONGs in pediatric patients usually present with painless proptosis, decreased visual acuity, visual fields, or color vision, while 
compression effects can cause hypothalamic symptoms or obstructive hydrocephalus due to the compression of the third ventricle and central retinal vein occlusion (CRVO) because of the compression of the central retinal vein. The aggressive form of ONGs is mainly encountered among adults and consists a life-threatening malignancy with poor prognosis. ONGs among adults are rapidly-growing neoplasms, which present with acute vision loss bilaterally due to the involvement of the optic chiasm (36,87-89).

Miyamoto et al first reported intense ${ }^{18} \mathrm{~F}-\mathrm{FDG}$ uptake by an ONG in an adult patient, guiding decision for surgical excision (90). Peng et al reported the utility of PET imaging with alpha- $\left[{ }^{11} \mathrm{C}\right]$ methyl-L-tryptophan in assessing the treatment response in a child with symptomatic ONG (91). Moharir et al, in a small retrospective study of pediatric patients with NF-1, implied that ${ }^{18} \mathrm{~F}$-FDG PET/CT may play a role in $\mathrm{ONG}$ surveillance by differentiating those tumors with a higher likelihood to advance and become symptomatic (92). Roselli et al reported the application of PET/CT with ${ }^{18} \mathrm{~F}$-fluorocholine $\left({ }^{18} \mathrm{~F}-\mathrm{FCH}\right)$, which targets the biosynthesis of cell membranes, in assessing treatment response of ONG in the setting of NF-1 (93). Rizzo et al, in a recent case report, described intense ${ }^{11} \mathrm{C}$-methionine $\left({ }^{11} \mathrm{C}\right.$-MET) activity by an $\mathrm{ONG}$ in an 80-year-old male patient (94). ${ }^{11} \mathrm{C}$-MET, is a PET-tracer, targeting amino acid utilization processes, which exhibits advantages over ${ }^{18} \mathrm{~F}$-FDG in detecting brain tumors, such as very low-level activity by inflammatory sites and by normal brain tissue (95). These data hold promise for the application of ${ }^{11} \mathrm{C}$-MET PET imaging in patients with ONG. However, larger prospective series of patients are required to elucidate the role of PET-imaging utilizing several PET-tracers beyond ${ }^{18} \mathrm{~F}-\mathrm{FDG}$ in the management of both benign and malignant ONG types.

\section{Ocular and orbital metastases}

Intra-ocular metastases are the most common intra-ocular malignancy, and often the first sign of systemic cancer spreading (96). The uvea, due to its rich vascularity, is the commonest metastatic site with the choroid being the most often metastatic location, while iris or ciliary body involvement is less commonly encountered (97). In patients with presumed uveal metastases, conventional imaging modalities (CT and MRI) often fail to detect the primary tumor. In this setting of patients, whole-body ${ }^{18} \mathrm{~F}$-FDG PET/CT studies can vitally contribute to accurate patient management, by successfully detecting the primary site and other metastatic lesions not seen on CT or MRI (98).

Orbital metastases stand for the most commonly encountered orbital malignancy, accounting for approximately $20 \%$ of all orbital cancers $(36,99)$, and being the first disease manifestation in $15 \%$ of the cases (100). Patients with orbital metastases usually present with diplopia, pain, palpable mass, proptosis, strabismus and visual loss. Breast, lung and prostatic cancer, together with cutaneous melanoma and neuroblastomas in children are the commonest tumors metastasizing to the orbit $(36,99,101)$. Orbital metastases exhibit ${ }^{18} \mathrm{~F}-\mathrm{FDG}$ avidity and therefore, ${ }^{18} \mathrm{~F}$-FDG PET/CT is a valuable diagnostic tool for these patients, enabling detection of the primary tumor, accurate disease staging and effective assessment of therapeutic response (99). Furthermore, orbital metastases originating from NETs can be successfully detected on SSTRs imaging with PET using ${ }^{68}$ Ga-DOTA-conjugated compounds $(18,101)$. Both ocular and orbital metastases harbor histological features identical to the primary malignancy, and therefore, immunohistochemistry should be employed in challenging cases, where imaging with advanced hybrid techniques fails to detect the primary disease site.

\section{Inflammatory orbital pseudotumor}

Inflammatory orbital pseudotumor (IOP), also known as idiopathic orbital pseudotumor, is a benign, non-infective, inflammatory condition of the orbit without systematic or locally identifiable causes, being reported as the most common cause of painful orbital mass and the third most common orbital disease following thyroid orbitopathy and lymphoproliferative disorder $(102,103)$. Typically, adult patients with IOP suffer from unilateral orbital pain, proptosis and impaired ocular movement, while in pediatric cohorts, IOP is bilaterally manifested, commonly associated with disc edema, uveitis and eosinophilia (103). Histopathologically, IOPs are characterized by a mixed inflammatory infiltrate, exhibiting a mixture of small lymphocytes, plasma cells and histiocytes $(36,102)$, while fibrosis is frequently encountered (104).

Imaging-wise, IOP is a great 'mimicker' (105). ${ }^{18} \mathrm{~F}-\mathrm{FDG}$ PET/CT scans demonstrate highly elevated radiotracer activity, in a lymphoma-mimicking pattern and biopsy is further required for establishing diagnosis (36). However, ${ }^{18} \mathrm{~F}-\mathrm{FDG}$ PET/CT can efficiently facilitate accurate monitoring of treatment response, in cases of non-surgical treatment approaches such as radiotherapy or administration of steroids, or in cases of incomplete surgical resection and lesion recurrence (106).

\section{Fibrous dysplasia}

Fibrous dysplasia (FD) of the bone is an uncommon, developmental benign skeletal disorder, characterized by the replacement of normal bone and normal bone marrow with abnormal fibro-osseous tissue, leading to bone deformity, pain, fractures and physical impairment (107). FD may affect a single skeletal site (monostotic FD), or multiple sites (polyostotic FD), and can be encountered either sporadically or in combination with extra-skeletal manifestations, including café-au-lait-like skin pigmentation and hyperfunctioning endocrinopathies. The combination of skeletal FD lesions with one or more extra-skeletal manifestations is termed McCune-Albright syndrome (MAS) $(107,108)$. FD involvement of the orbital bones can lead to hypertelorism, exophthalmos, vision impairment or even vision loss, due to narrowing of the optic nerve canal and subsequent optic nerve compression (36). Typically, bone FD lesions present a characteristic ground-glass appearance on the CT scan with expansion of the medullary cavity (Fig. 6).

Bone FD lesions may present ${ }^{18}$ F-FDG-negative $(109,110)$ or exhibit variable degrees of ${ }^{18}$ F-FDG activity on PET/CT, mimicking malignancy (111-116). However, co-registration with CT enables confident characterization of lesions and avoidance of erroneous interpretation of ${ }^{18} \mathrm{~F}-\mathrm{FDG}$ positive skeletal findings. Moreover, intensely increasing ${ }^{18} \mathrm{~F}-\mathrm{FDG}$ activity 


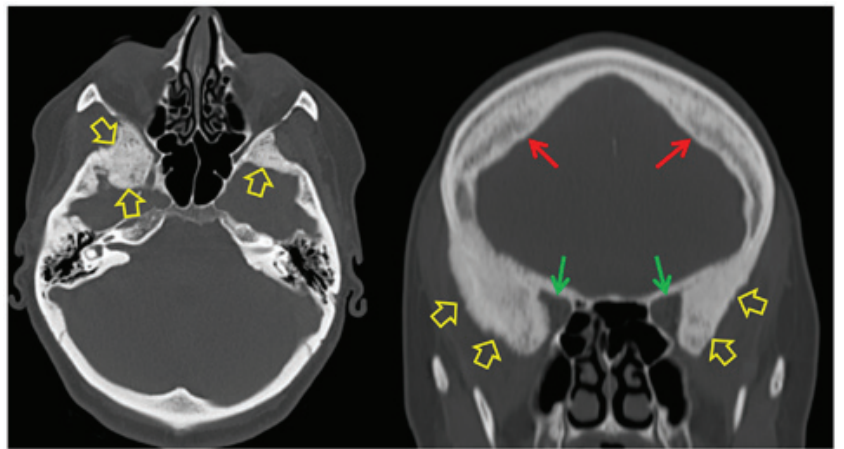

Figure 6. A 42-year-old female with fibrous dysplasia of bone. Left image, axial CT image of the skull shows bony expansion and the typical ground glass appearance involving the sphenoid bones bilaterally (open yellow arrows). Right image, coronal multi-planar (MPR) CT image of the skull demonstrates (green arrows) the reduction - more pronounced on the right- of the orbital volume, due to the sphenoidal fibrous dysplasia involvement (open yellow arrows). Furthermore, hyperostosis frontalis interna is recognized (red arrows).
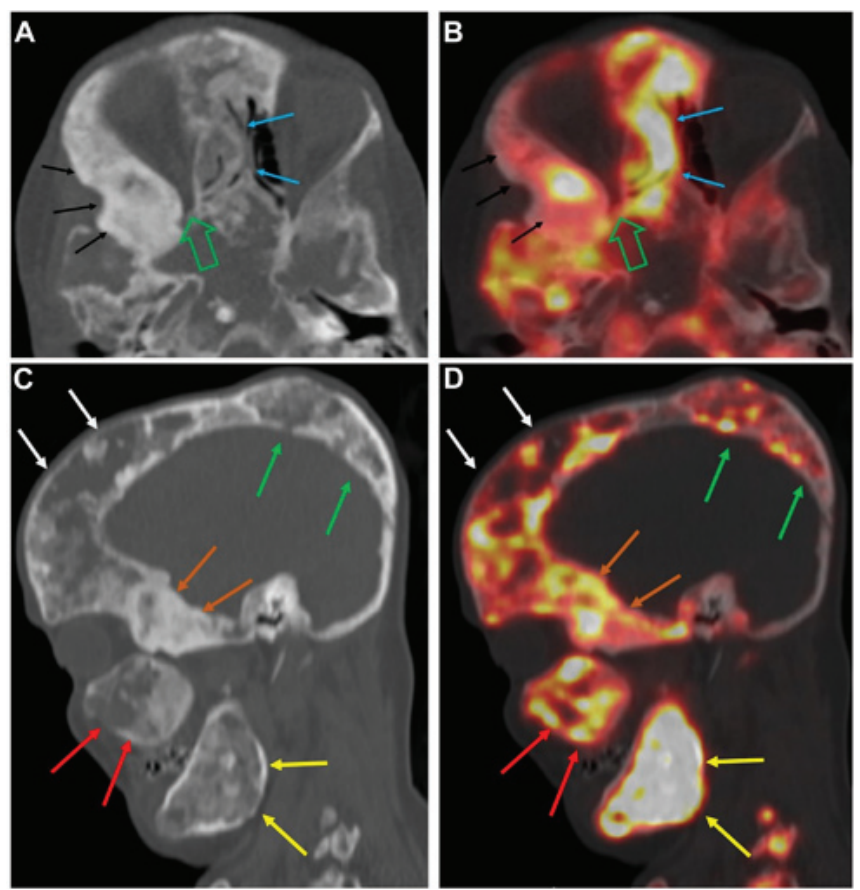

Figure 7. A 46-year-old female with extensive fibrous dysplastic bone lesions with both hypodense and hyperdense lesions on the CT. (A and B) Axial CT and fused ${ }^{18} \mathrm{~F}-\mathrm{NaF}$ PET/CT images of the skull showing marked narrowing of the right orbital apex (open green arrow) and FD lesions involving the nasal bones (blue arrows) and the right sphenoid bone (black arrows), with abnormally increased ${ }^{18} \mathrm{~F}-\mathrm{NaF}$ uptake. (C and D) Sagittal CT and fused ${ }^{18} \mathrm{~F}-\mathrm{NaF}$ PET/CT images of the skull showing FD lesions involving the right frontal bone (white arrows), right parietal bone (green arrows), right sphenoid (orange arrows), right maxilla (red arrows), and right ramus of mandible (yellow arrows), all of which exhibit abnormally elevated ${ }^{18} \mathrm{~F}-\mathrm{NaF}$ activity. (Figure is courtesy of Dr M.T. Collins and Dr A.M. Boyce, National Institute of Dental and Craniofacial Research (NIDCR), National Institutes of Health (NIH), Bethesda, MD, USA ${ }^{18} \mathrm{~F}-\mathrm{NaF},{ }^{18} \mathrm{~F}$-sodium fluoride; $\mathrm{PET} / \mathrm{CT}$, positron emission tomography/computed tomography; FD, fibrous dysplasia.

by FD lesions should raise suspicion for the rare possibility of malignant transformation $(<2 \%$ of all FD cases) $(117,118)$. In this particular setting of malignantly transformed FD lesions, whole-body ${ }^{18} \mathrm{~F}$-FDG PET/CT has a role in the early detection of the transformation and in the management of these patients, by facilitating accurate biopsy guidance, staging, optimal surgical planning, detection of recurrence and efficient follow-up (118).

Bone FD has been visualized with conventional SSTRs scintigraphy using ${ }^{111}$ In-pentetreotide, suggesting cell surface over-expression of SSTRs by fibrous dysplastic cells (119). The introduction of ${ }^{68} \mathrm{Ga}$-DOTA-conjugated-peptides into clinical practice has enabled the employment of PET-imaging in targeting lesions, characterized by SSTRs-overexpressi on (18,19-33). Papadakis et al reported intensely increased ${ }^{68} \mathrm{Ga}$-DOTATE (radiolabeled somatostatin analogue suitable for PET-imaging, which targets SSTRs) activity on PET/CT, by a biopsy proven FD lesion in the temporal bone (22). These data suggest the potential application of PET/CT with ${ }^{68} \mathrm{Ga}$-DOTA-conjugated-peptides in assessing and monitoring FD activity or even prognostic value of ${ }^{68} \mathrm{Ga}$-DOTATATE uptake in FD lesions that need to be further investigated. Furthermore, bone FD can be effectively targeted with ${ }^{18} \mathrm{~F}-\mathrm{NaF}$ PET/CT (Fig. 7), which has been shown to be strongly associated with bone turnover markers in the blood, while exhibiting prognostic value for clinical manifestations of the disorder (120-124).

\section{PET-MRI}

PET/MRI combines the functional information of PET with the superior soft-tissue contrast and the functional MR-sequences, providing enhanced oncologic applications, especially in small anatomic regions with complex anatomy such as the orbital and ocular space. Furthermore, pediatric and pregnant oncologic patients with need for follow-up studies, can take advantage of the reduced radiation exposure of PET/MRI compared to PET/CT. In recent years, PET-MRI technology has evolved into an established clinical diagnostic tool, with instrumentation advancements leading to PET detectors compatible with the MRI field, enabling simultaneous PET and MRI acquisition $(125,126)$. These advancements hold promise for superior diagnostic capabilities, improved image quality with reduced PET-image noise, more accurate co-registration of PET-data with MRI anatomy, correction for respiratory, heart and bulk patient motion, and temporal synchronization of the data acquired by the two modalities (4).

PET/MRI has already been widely employed in the management of head and neck cancers, providing incremental diagnostic information for the local staging of the primary tumor and regional lymph node status, while facilitating more accurate radiation treatment planning $(4,36,127,128)$. Patients with lymphomas, neuroblastomas and soft tissue sarcomas may benefit from PET/MRI evaluation, which holds promise for improved oncologic applications (36,127-130), with further studies being needed in order to elucidate the role and the added value of this modality in ophthalmic oncology.

\section{Conclusions}

The introduction of hybrid PET/CT and PET/MRI systems into clinical practice has opened new broad horizons in ophthalmic oncology. The challenges of managing orbital and ocular tumors, can be addressed more effectively, through 
these multimodal imaging approaches. For the detection of primary orbital and ocular tumors, ${ }^{18} \mathrm{~F}-\mathrm{FDG}$ PET/CT imaging does not seem to offer additional information over clinical evaluation and conventional anatomic imaging modalities (CT, MRI and US). However, ${ }^{18} \mathrm{~F}$-FDG PET/CT has an established role for patients with OL and OAL both at initial staging and post-treatment assessment. In addition, despite contradictory data, patients with UM most likely will have significant benefit from evaluation with ${ }^{18} \mathrm{~F}$-FDG PET/CT for staging and follow-up. Moreover, ${ }^{18} \mathrm{~F}$-FDG PET/CT is of utmost value for patients presenting with intraocular or orbital metastases, and unknown primary cancer. For the remaining set of ophthalmic tumors, ${ }^{18} \mathrm{~F}$-FDG PET/CT seems to be of value for advanced malignancies with an increased suspicion of regional or distant disease dissemination. PET/CT with ${ }^{18} \mathrm{~F}-\mathrm{NaF}$ is the imaging modality of choice for the evaluation and monitoring of disease activity in patients with FD of the orbital bones. Finally, in patients with well-differentiated NETs, PET/CT using ${ }^{68} \mathrm{Ga}$-DOTA-compounds is the imaging technique of reference for detecting orbital or ocular metastases. The development of novel cancer-specific PET-tracers together with the advent of clinical simultaneous PET/MRI systems and the employment of artificial intelligence (AI)-based multi-modal predictive models (130), hold promise for more efficient personalized management strategies of ophthalmic oncology patients.

\section{Acknowledgements}

Not applicable.

\section{Funding}

Part of this study was financially supported by the Stavros Niarchos Foundation within the framework of the project ARCHERS ('Advancing Young Researchers' Human Capital in Cutting Edge Technologies in the Preservation of Cultural Heritage and the Tackling of Societal Challenges').

\section{Availability of data and materials}

Not applicable.

\section{Authors' contributions}

GZP and MSK conceived and designed the study. GZP and MSK researched the literature, performed analysis and interpretation of data and drafted the manuscript. AHK, DE, ETD, OZ, KM, CM, UB, IP, AS, IK KP, PK, GAK, DAS and AT critically revised the article for important intellectual content, and assisted in the literature search for this review article. All authors agree to be accountable for all aspects of the work in ensuring that questions related to the accuracy or integrity of any part of the work are appropriately investigated, and finally approved the version of the manuscript to be published. IK also designed Fig. 1.

\section{Ethics approval and consent to participate}

The patient images presented in Figs. 2-7 were obtained after acquiring ethics approval from the relevant ethics committees and patient consent. The images in Figs. 2-6 were provided by the author DE, from the PET/CT department of Evangelismos Hospital in Athens; all patients have provided written consent forms prior to scanning. Fig. 7 was provided by esteemed physicians at the NIH, with whom the senior and corresponding author of the article collaborates. All study participants at the NIH clinical protocols provided all the extensive consent forms and strict ethical approval documents that the NIH standards require.

\section{Patient consent for publication}

Not applicable.

\section{Competing interests}

DAS is the Editor-in-Chief for the journal, but had no personal involvement in the reviewing process, or any influence in terms of adjudicating on the final decision, for this article. All the other authors declare that they have no competing interests.

\section{References}

1. Boellaard R, Delgado-Bolton R, Oyen WJG, Giammarile F, Tatsch K, Eschner W, Verzijlbergen FJ, Barrington SF, Pike LC, Weber WA, et al; European Association of Nuclear Medicine (EANM): FDG PET/CT: EANM procedure guidelines for tumour imaging: version 2.0. Eur J Nucl Med Mol Imaging 42: 328-354, 2015.

2. Pfannenberg AC, Aschoff P, Brechtel K, Müller M, Klein M, Bares R, Claussen CD and Eschmann SM: Value of contrast-enhanced multiphase CT in combined PET/CT protocols for oncological imaging. Br J Radiol 80: 437-445, 2007.

3. Bashir U, Mallia A, Stirling J, Joemon J, MacKewn J, Charles-Edwards G, Goh V and Cook GJ: PET/MRI in Oncological Imaging: State of the Art. Diagnostics (Basel) 5: 333-357, 2015.

4. Broski SM, Goenka AH, Kemp BJ and Johnson GB: Clinical PET/MRI: 2018 Update. AJR Am J Roentgenol 211: 295-313, 2018.

5. Papadakis GZ, Manikis GC, Hannah-Shmouni F, O'Brien KJ, Gahl WA and Estrada-Veras JI: Higher metabolic activity seen on ${ }^{18} \mathrm{~F}$-FDG PET/CT, in the adrenal glands of patients with Erdheim-Chester Disease harboring the BRAF V600E mutation. Pediatr Blood Cancer 64 (Suppl): S29-S29, 2017.

6. Papadakis GZ, Patronas NJ, Chen CC, Carney JA and Stratakis CA: Combined PET/CT by ${ }^{18} \mathrm{~F}$-FDOPA, ${ }^{18} \mathrm{~F}-\mathrm{FDA}$, ${ }^{18} \mathrm{~F}-\mathrm{FDG}$, and MRI correlation on a patient with Carney triad. Clin Nucl Med 40: 70-72, 2015.

7. Diker-Cohen T, Abraham SB, Rauschecker M, Papadakis GZ, Munir KM, Brown E, Lyssikatos C, Belyavskaya E, Merino M and Stratakis CA: Reninoma presenting in pregnancy. J Clin Endocrinol Metab 99: 2625-2626, 2014.

8. Karageorgiadis AS, Papadakis GZ, Biro J, Keil MF, Lyssikatos C, Quezado MM, Merino M, Schrump DS, Kebebew E, Patronas NJ, et al: Ectopic adrenocorticotropic hormone and corticotropin-releasing hormone co-secreting tumors in children and adolescents causing cushing syndrome: A diagnostic dilemma and how to solve it. J Clin Endocrinol Metab 100: 141-148, 2015.

9. Hammoud DA, Boulougoura A, Papadakis GZ, Wang J, Dodd LE, Rupert A, Higgins J, Roby G, Metzger D, Laidlaw E, et al: Increased metabolic activity on ${ }^{18} \mathrm{~F}$-Fluorodeoxyglucose positron emission tomography-computed tomography in human immunodeficiency virus-associated immune reconstitution inflammatory syndrome. Clin Infect Dis 68: 229-238, 2019.

10. Hannah-Shmouni F, Papadakis GZ, Stratakis CA and Blau J: Enlarging hypermetabolic nodule: Benign non-functional adrenocortical adenoma. BMJ Case Rep 2017: bcr2017220820, 2017.

11. Papadakis GZ, Millo C and Stratakis CA: Benign hormonesecreting adenoma within a larger adrenocortical mass showing intensely increased activity on ${ }^{18} \mathrm{~F}-\mathrm{FDG}$ PET/CT. Endocrine 54: 269-270, 2016. 
12. Papadakis GZ, Holland SM, Quezado $M$ and Patronas NJ: Adrenal cryptococcosis in an immunosuppressed patient showing intensely increased metabolic activity on ${ }^{18} \mathrm{~F}-\mathrm{FDG}$ PET/CT. Endocrine 54: 834-836, 2016.

13. Papadakis GZ, Millo C, Bagci U, Patronas NJ and Stratakis CA: Talc pleurodesis with intense ${ }^{18} \mathrm{~F}-\mathrm{FDG}$ activity but no ${ }^{68}$ Ga-DOTA-TATE activity on PET/CT. Clin Nucl Med 40: 819-820, 2015.

14. Bastawrous S, Bhargava P, Behnia F, Djang DS and Haseley DR: Newer PET application with an old tracer: Role of ${ }^{18} \mathrm{~F}-\mathrm{NaF}$ skeletal PET/CT in oncologic practice. Radiographics 34: 1295-1316, 2014

15. Papadakis GZ, Jha S, Bhattacharyya T, Millo C, Tu TW, Bagci U, Marias K, Karantanas AH and Patronas NJ: ${ }^{18} \mathrm{~F}-\mathrm{NaF}$ PET/CT in extensive melorheostosis of the axial and appendicular Skeleton With Soft-Tissue Involvement. Clin Nucl Med 42: 537-539, 2017.

16. Papadakis GZ, Jha S, Karantanas AH, Marias K, Bagci U and Bhattacharyya T: Prospective evaluation of the application of ${ }^{18} \mathrm{~F}-\mathrm{NaF}$ PET/CT imaging in melorheostosis. Eur J Nucl Med Mol Imaging 45 (Suppl 1): S231-S232, 2018.

17. Papadakis GZ, Millo C, Bagci U, Blau J and Collins MT: ${ }^{18} \mathrm{~F}-\mathrm{NaF}$ and ${ }^{18}$ F-FDG PET/CT in Gorham-Stout Disease. Clin Nucl Med 41: 884-885, 2016

18. Papadakis GZ, Millo C, Bagci U, Patronas NJ and Collins MT: Value of ${ }^{18} \mathrm{~F}-\mathrm{NaF}$ PET/CT imaging in the assessment of Gorham-Stout disease activity. Eur J Nucl Med Mol Imaging 43 (Suppl 1): S597-S597, 2016.

19. Hofman MS, Lau WF and Hicks RJ: Somatostatin receptor imaging with ${ }^{68} \mathrm{Ga}$ DOTATATE PET/CT: Clinical utility, normal patterns, pearls, and pitfalls in interpretation. Radiographics 35 500-516, 2015.

20. Tirosh A, Papadakis GZ, Millo C, Hammoud D, Sadowski SM, Herscovitch P, Pacak K, Marx SJ, Yang L, Nockel P, et al: Prognostic utility of total ${ }^{68} \mathrm{Ga}$-DOTATATE-avid tumor volume in patients with neuroendocrine tumors. Gastroenterology 154: 998-1008.e1, 2018

21. Tirosh A, Papadakis GZ, Millo C, Sadowski SM, Herscovitch P, Pacak K, Marx SJ, Yang L, Nockel P, Shell J, et al: Association between neuroendocrine tumors biomarkers and primary tumor site and disease type based on total ${ }^{68} \mathrm{Ga}$-DOTATATE-Avid tumor volume measurements. Eur J Endocrinol 176: 575-582, 2017.

22. Papadakis GZ, Millo C, Sadowski SM, Karantanas AH, Bagci U and Patronas NJ: Fibrous Dysplasia Mimicking Malignancy on ${ }^{68} \mathrm{Ga}$-DOTATATE PET/CT. Clin Nucl Med 42: 209-210, 2017.

23. Papadakis GZ, Sadowski SM, Bagci U and Millo C: Application of ${ }^{68} \mathrm{Ga}$-DOTA-TATE PET/CT in metastatic neuroendocrine tumor of gastrointestinal origin. Ann Gastroenterol 30: 130, 2017.

24. Papadakis GZ, Millo C, Jassel IS, Bagci U, Sadowski SM, Karantanas AH and Patronas NJ: ${ }^{18} \mathrm{~F}-\mathrm{FDG}$ and ${ }^{68} \mathrm{Ga}$-DOTATATE PET/CT in von Hippel-Lindau disease-associated retinal hemangioblastoma. Clin Nucl Med 42: 189-190, 2017.

25. Papadakis GZ, Millo C, Karantanas AH, Bagci U and Patronas NJ: Avascular necrosis of the hips with increased activity on ${ }^{68} \mathrm{Ga}$-DOTATATE PET/CT. Clin Nucl Med 42: 214-215, 2017.

26. Papadakis GZ, Millo C, Sadowski SM, Karantanas AH, Bagci $\mathrm{U}$ and Patronas NJ: Breast fibroadenoma with increased activity on ${ }^{68} \mathrm{Ga}$ DOTATATE PET/CT. Clin Nucl Med 42: 145-146, 2017

27. Papadakis GZ, Millo C, Sadowski SM, Bagci U and Patronas NJ: Kidney Tumor in a von Hippel-Lindau (VHL) patient with intensely increased activity on ${ }^{68} \mathrm{Ga}-\mathrm{DOTA}-\mathrm{TATE}$ PET/CT. Clin Nucl Med 41: 970-971, 2016

28. El-Maouche D, Sadowski SM, Papadakis GZ, Guthrie L Cottle-Delisle C, Merkel R, Millo C, Chen CC, Kebebew E and Collins MT: ${ }^{68} \mathrm{Ga}$-DOTATATE for tumor localization in tumor-induced osteomalacia. J Clin Endocrinol Metab 101: 3575-3581, 2016.

29. Papadakis GZ, Millo C, Sadowski SM, Bagci U and Patronas NJ: Epididymal cystadenomas in von Hippel-Lindau disease showing increased activity on ${ }^{68} \mathrm{Ga}$ DOTATATE PET/CT. Clin Nucl Med 41: 781-782, 2016.

30. Papadakis GZ, Millo C, Sadowski SM, Bagci U and Patronas NJ: Endolymphatic sac tumor showing increased activity on ${ }^{68}$ Ga-DOTATATE PET/CT. Clin Nucl Med 41: 783-784, 2016.

31. Papadakis GZ, Millo C, Bagci U, Sadowski SM and Stratakis CA: Schmorl nodes can cause increased ${ }^{68} \mathrm{Ga}$-DOTATATE activity on $\mathrm{PET} / \mathrm{CT}$, mimicking metastasis in patients with neuroendocrine malignancy. Clin Nucl Med 41: 249-250, 2016.
32. Papadakis GZ, Bagci U, Sadowski SM, Patronas NJ and Stratakis CA: Ectopic ACTH and CRH co-secreting tumor localized by ${ }^{68} \mathrm{Ga}$-DOTA-TATE PET/CT. Clin Nucl Med 40: 576-578, 2015.

33. Tirosh A, Papadakis GZ, Millo C, Sadowski SM, Herscovitch P, Pacak K, Marx SJ, Yang L, Nockel P, Shell J, et al: High total ${ }^{68} \mathrm{Ga}$-DOTATATE-Avid Tumor Volume (TV) is associated with low progression-free survival and high disease-specific mortality rate in patients with neuroendocrine tumors. Endocrine Abstracts 49: OC7.3, 2017.

34. Honavar SG and Manjandavida FP: Recent Advances in Orbital Tumors - A Review of Publications from 2014-2016. Asia Pac J Ophthalmol (Phila) 6: 153-158, 2017

35. Hui KH, Pfeiffer ML and Esmaeli B: Value of positron emission tomography/computed tomography in diagnosis and staging of primary ocular and orbital tumors. Saudi J Ophthalmol 26: 365-371, 2012.

36. Purohit BS, Vargas MI, Ailianou A, Merlini L, Poletti PA, Platon A, Delattre BM, Rager O, Burkhardt K and Becker M: Orbital tumours and tumour-like lesions: Exploring the armamentarium of multiparametric imaging. Insights Imaging 7: 43-68, 2016.

37. English JF and Sullivan TJ: The Role of FDG-PET in the diagnosis and staging of ocular adnexal lymphoproliferative disease. Orbit 34: 284-291, 2015.

38. Valenzuela AA, Allen C, Grimes D, Wong D and Sullivan TJ: Positron emission tomography in the detection and staging of ocular adnexal lymphoproliferative disease. Ophthalmology 113: 2331-2337, 2006.

39. Roe RH, Finger PT, Kurli M, Tena LB and Iacob CE: Whole-body positron emission tomography/computed tomography imaging and staging of orbital lymphoma. Ophthalmology 113: 1854-1858, 2006.

40. Suga K, Yasuhiko K, Hiyama A, Takeda K and Matsunaga N: ${ }^{18}$ F-FDG PET/CT findings in a patient with bilateral orbital and gastric mucosa-associated lymphoid tissue lymphomas. Clin Nucl Med 34: 589-593, 2009

41. Gayed I, Eskandari MF, McLaughlin P, Pro B, Diba R and Esmaeli B: Value of positron emission tomography in staging ocular adnexal lymphomas and evaluating their response to therapy. Ophthalmic Surg Lasers Imaging 38: 319-325, 2007.

42. Sallak A, Besson FL, Pomoni A, Christinat A, Adler M, Aegerter JP, Nguyen C, de Leval L, Frossard V and Prior JO: Conjunctival MALT lymphoma: Utility of FDG PET/CT for diagnosis, staging, and evaluation of treatment response. Clin Nucl Med 39: 295-297, 2014.

43. Yildirim-Poyraz N, Ozdemir E, Basturk A, Kilicarslan A and Turkolmez S: PET/CT findings in a case with FDG-avid disseminated lacrimal gland MALToma with sequential development of large B-cell lymphoma and gastric MALToma. Clin Nucl Med 40: 141-145, 2015.

44. Fujii H, Tanaka H, Nomoto Y, Harata N, Oota S, Isogai J and Yoshida K: Usefulness of ${ }^{18} \mathrm{~F}-\mathrm{FDG}$ PET/CT for evaluating response of ocular adnexal lymphoma to treatment. Medicine (Baltimore) 97: e0543, 2018.

45. Hu DN, Yu GP, McCormick SA, Schneider S and Finger PT: Population-based incidence of uveal melanoma in various races and ethnic groups. Am J Ophthalmol 140: 612-617, 2005.

46. Singh AD, Turell ME and Topham AK: Uveal melanoma: Trends in incidence, treatment, and survival. Ophthalmology 118: 1881-1885, 2011

47. Finger PT, Kurli M, Wesley P, Tena L, Kerr KR and Pavlick A: Whole body PET/CT imaging for detection of metastatic choroidal melanoma. Br J Ophthalmol 88: 1095-1097, 2004

48. Reddy S, Kurli M, Tena LB and Finger PT: PET/CT imaging: Detection of choroidal melanoma. Br J Ophthalmol 89: 1265-1269, 2005

49. Finger PT, Chin K and Iacob CE: 18-Fluorine-labelled 2-deoxy-2-fluoro-D-glucose positron emission tomography/computed tomography standardised uptake values: A non-invasive biomarker for the risk of metastasis from choroidal melanoma. Br J Ophthalmol 90: 1263-1266, 2006.

50. Matsuo T, Ogino Y, Ichimura K, Tanaka T and Kaji M: Clinicopathological correlation for the role of fluorodeoxyglucose positron emission tomography computed tomography in detection of choroidal malignant melanoma. Int J Clin Oncol 19: 230-239, 2014

51. McCannel TA, Reddy S, Burgess BL and Auerbach M: Association of positive dual-modality positron emission tomography/computed tomography imaging of primary choroidal melanoma with chromosome 3 loss and tumor size. Retina 30: $146-151,2010$ 
52. Papastefanou VP, Islam S, Szyszko T, Grantham M, Sagoo MS and Cohen VML: Metabolic activity of primary uveal melanoma on PET/CT scan and its relationship with monosomy 3 and other prognostic factors. Br J Ophthalmol 98: 1659-1665, 2014.

53. Kurli M, Reddy S, Tena LB, Pavlick AC and Finger PT: Whole body positron emission tomography/computed tomography staging of metastatic choroidal melanoma. Am J Ophthalmol 140: 193-199, 2005.

54. Freton A, Chin KJ, Raut R, Tena LB, Kivelä T and Finger PT: Initial PET/CT staging for choroidal melanoma: AJCC correlation and second nonocular primaries in 333 patients. Eur J Ophthalmol 22: 236-243, 2012.

55. Strobel K, Bode B, Dummer R, Veit-Haibach P, Fischer DR, Imhof L, Goldinger S, Steinert HC and von Schulthess GK: Limited value of ${ }^{18} \mathrm{~F}$-FDG PET/CT and S-100B tumour marker in the detection of liver metastases from uveal melanoma compared to liver metastases from cutaneous melanoma. Eur J Nucl Med Mol Imaging 36: 1774-1782, 2009.

56. Orcurto V, Denys A, Voelter V, Schalenbourg A, Schnyder P Zografos L, Leyvraz S, Delaloye AB and Prior JO: (18) F-fluorodeoxyglucose positron emission tomography/computed tomography and magnetic resonance imaging in patients with liver metastases from uveal melanoma: Results from a pilot study. Melanoma Res 22: 63-69, 2012

57. Ries LAG, Smith MA, Gurney JG, Linet M, Tamra T, Young JL and Bunin GR (eds): Cancer incidence and survival among children and adolescents: United States SEER program 1975-1995. NIH Pub. No. 99-4649. National Cancer Institute, Bethesda, MD, 1999.

58. Jakobiec FA, Tso MO, Zimmerman LE and Danis $P$. Retinoblastoma and intracranial malignancy. Cancer 39: 2048-2058, 1977.

59. de Jong MC, Kors WA, de Graaf P, Castelijns JA, Kivelä T and Moll AC: Trilateral retinoblastoma: A systematic review and meta-analysis. Lancet Oncol 15: 1157-1167, 2014.

60. Kamihara J, Bourdeaut F, Foulkes WD, Molenaar JJ, Mossé YP, Nakagawara A, Parareda A, Scollon SR, Schneider KW Skalet AH, et al: Retinoblastoma and Neuroblastoma Predisposition and Surveillance. Clin Cancer Res 23: e98-e106, 2017.

61. Yamanaka R, Hayano A and Takashima Y: Trilateral retinoblastoma: A systematic review of 211 cases. Neurosurg Rev 42 : 39-48, 2019.

62. Honavar SG, Manjandavida FP and Reddy VAP: Orbital retinoblastoma: An update. Indian J Ophthalmol 65: 435-442, 2017.

63. Radhakrishnan V, Kumar R, Malhotra A and Bakhshi S: Role of PET/CT in staging and evaluation of treatment response after 3 cycles of chemotherapy in locally advanced retinoblastoma: A prospective study. J Nucl Med 53: 191-198, 2012.

64. Yu GP, Hu DN, McCormick S and Finger PT: Conjunctival melanoma: Is it increasing in the United States? Am J Ophthalmol 135: 800-806, 2003.

65. Folberg R, McLean IW and Zimmerman LE: Malignant melanoma of the conjunctiva. Hum Pathol 16: 136-143, 1985.

66. Damian A, Gaudiano J, Engler H and Alonso O: (18)F-FDG PET-CT for Staging of Conjunctival Melanoma. World J Nucl Med 12: 45-47, 2013.

67. Tuomaala S and Kivelä T: Metastatic pattern and survival in disseminated conjunctival melanoma: Implications for sentine lymph node biopsy. Ophthalmology 111: 816-821, 2004

68. Kurli M, Chin K and Finger PT: Whole-body 18 FDG PET/CT imaging for lymph node and metastatic staging of conjunctival melanoma. Br J Ophthalmol 92: 479-482, 2008.

69. Tsai SY, Shiau YC, Wang SY and Wu YW: Conjunctival Melanoma on ${ }^{18}$ F-FDG PET/CT as a Second Primary Cancer. Clin Nucl Med 41: 237-238, 2016.

70. Muqit MM, Foot B, Walters SJ, Mudhar HS, Roberts F and Rennie IG: Observational prospective cohort study of patients with newly-diagnosed ocular sebaceous carcinoma. Br J Ophthalmol 97: 47-51,2013.

71. Yin VT, Merritt HA, Sniegowski M and Esmaeli B: Eyelid and ocular surface carcinoma: Diagnosis and management. Clin Dermatol 33: 159-169, 2015.

72. Shields JA, Demirci H, Marr BP, Eagle RC Jr and Shields CL: Sebaceous carcinoma of the eyelids: Personal experience with 60 cases. Ophthalmology 111: 2151-2157, 2004

73. Baek CH, Chung MK, Jeong HS, Son YI, Choi J, Kim YD, Choi JY, Kim HJ and Ko YH: The clinical usefulness of (18) F-FDG PET/CT for the evaluation of lymph node metastasis in periorbital malignancies. Korean J Radiol 10: 1-7, 2009.
74. Krishna SM, Finger PT, Chin K and Lacob CE: 18-FDG PET/CT staging of ocular sebaceous cell carcinoma. Graefes Arch Clin Exp Ophthalmol 245: 759-760, 2007.

75. Ishiguro $\mathrm{Y}$, Homma S, Yoshida T, Ohno Y, Ichikawa N Kawamura H, Hata H, Kase S, Ishida S, Okada-Kanno H, et al: Usefulness of PET/CT for early detection of internal malignancies in patients with Muir-Torre syndrome: Report of two cases. Surg Case Rep 3: 71, 2017.

76. Faustina M, Diba R, Ahmadi MA and Esmaeli B: Patterns of regional and distant metastasis in patients with eyelid and periocular squamous cell carcinoma. Ophthalmology 111: 1930-1932, 2004.

77. Donaldson MJ, Sullivan TJ, Whitehead KJ and Williamson RM: Squamous cell carcinoma of the eyelids. Br J Ophthalmol 86: $1161-1165,2002$

78. Soysal HG and Markoç F: Invasive squamous cell carcinoma of the eyelids and periorbital region. Br J Ophthalmol 91: 325-329, 2007.

79. Reifler DM and Hornblass A: Squamous cell carcinoma of the eyelid. Surv Ophthalmol 30: 349-365, 1986.

80. Yi JS, Kim JS, Lee JH, Choi SH, Nam SY, Kim SY and Roh JL: ${ }^{18}$ F-FDG PET/CT for detecting distant metastases in patients with recurrent head and neck squamous cell carcinoma. J Surg Oncol 106: 708-712, 2012

81. Lin LF, Chang CY and Cherng SC: Advanced squamous cell carcinoma of the bulbar conjunctiva seen on PET/CT. Clin Nucl Med 33: 929-930, 2008

82. Abdelmalik AG, Fajnwaks P, Osman MM and Nguyen NC: Squamous cell carcinoma of the bulbar conjunctiva seen on F-18 FDG PET/CT. Clin Nucl Med 35: 962-964, 2010.

83. Jurdy L, Merks JHM, Pieters BR, Mourits MP, Kloos RJ, Strackee SD and Saeed P: Orbital rhabdomyosarcomas: A review. Saudi J Ophthalmol 27: 167-175, 2013

84. Norman G, Fayter D, Lewis-Light K, Chisholm J, McHugh K, Levine D, Jenney M, Mandeville H, Gatz S and Phillips B: An emerging evidence base for PET-CT in the management of childhood rhabdomyosarcoma: Systematic review. BMJ Open 5: e006030, 2015.

85. Harrison DJ, Parisi MT and Shulkin BL: The Role of ${ }^{18}$ F-FDG-PET/CT in Pediatric Sarcoma. Semin Nucl Med 47: 229-241, 2017.

86. Teixeira SR, Martinez-Rios C, Hu L and Bangert BA: Clinical applications of pediatric positron emission tomography-magnetic resonance imaging. Semin Roentgenol 49: 353-366, 2014.

87. Nair AG, Pathak RS, Iyer VR and Gandhi RA: Optic nerve glioma: An update. Int Ophthalmol 34: 999-1005, 2014.

88. Becker M, Masterson K, Delavelle J, Viallon M, Vargas MI and Becker CD: Imaging of the optic nerve. Eur J Radiol 74: 299-313, 2010.

89. Campen CJ and Gutmann DH: Optic Pathway Gliomas in Neurofibromatosis Type 1. J Child Neurol 33: 73-81, 2018.

90. Miyamoto J, Sasajima H, Owada K and Mineura K: Surgical decision for adult optic glioma based on $[18 \mathrm{~F}]$ fluorodeoxyglucose positron emission tomography study. Neurol Med Chir (Tokyo) 46: 500-503, 2006.

91. Peng F, Juhasz C, Bhambhani K, Wu D, Chugani DC and Chugani HT: Assessment of progression and treatment response of optic pathway glioma with positron emission tomography using alpha-[(11)C]methyl-L-tryptophan. Mol Imaging Biol 9: 106-109, 2007.

92. Moharir M, London K, Howman-Giles R and North K: Utility of positron emission tomography for tumour surveillance in children with neurofibromatosis type 1. Eur J Nucl Med Mol Imaging 37: 1309-1317, 2010.

93. Roselli F, Pisciotta NM, Aniello MS, Niccoli-Asabella A, Defazio G, Livrea P and Rubini G: Brain F-18 Fluorocholine PET/CT for the assessment of optic pathway glioma in neurofibromatosis-1. Clin Nucl Med 35: 838-839, 2010.

94. Rizzo V, Mattoli MV, Trevisi G, Coli A, Calcagni ML and Montano N: Optic nerve glioblastoma detected by ${ }^{11} \mathrm{C}$-Methionine brain PET/CT. Rev Esp Med Nucl Imagen Mol 37: 259-260, 2018.

95. Nakajima R, Kimura K, Abe K and Sakai S: ${ }^{11} \mathrm{C}$-methionine PET/CT findings in benign brain disease. Jpn J Radiol 35: 279-288, 2017.

96. Konstantinidis L and Damato B: Intraocular Metastases - A Review. Asia Pac J Ophthalmol (Phila) 6: 208-214, 2017.

97. Konstantinidis L, Rospond-Kubiak I, Zeolite I, Heimann H, Groenewald C, Coupland SE and Damato B: Management of patients with uveal metastases at the Liverpool Ocular Oncology Centre. Br J Ophthalmol 98: 92-98, 2014. 
98. Donaldson MJ, Pulido JS, Mullan BP, Inwards DJ, Cantrill H, Johnson MR and Han MK: Combined positron emission tomography/computed tomography for evaluation of presumed choroidal metastases. Clin Exp Ophthalmol 34: 846-851, 2006.

99. Shields JA, Shields CL and Scartozzi R: Survey of 1264 patients with orbital tumors and simulating lesions: The 2002 Montgomery Lecture, part 1. Ophthalmology 111: 997-1008, 2004.

100. Valenzuela AA, Archibald CW, Fleming B, Ong L, O'Donnell B, Crompton J J, Selva D, McNab AA and Sullivan TJ: Orbital metastasis: Clinical features, management and outcome. Orbit 28: 153-159, 2009.

101. Das S, Pineda G, Goff L, Sobel R, Berlin J and Fisher G: The eye of the beholder: Orbital metastases from midgut neuroendocrine tumors, a two institution experience. Cancer Imaging 18: 47, 2018

102. Ding ZX, Lip G and Chong V: Idiopathic orbital pseudotumour. Clin Radiol 66: 886-892, 2011.

103. Weber AL, Romo LV and Sabates NR: Pseudotumor of the orbit. Clinical, pathologic, and radiologic evaluation. Radiol Clin North Am 37: 151-168, xi, 1999.

104.Pakdaman MN, Sepahdari AR and Elkhamary SM: Orbital inflammatory disease: Pictorial review and differential diagnosis. World J Radiol 6: 106-115, 2014.

105.Patnana M, Sevrukov AB, Elsayes KM, Viswanathan C, Lubner $\mathrm{M}$ and Menias CO: Inflammatory pseudotumor: The great mimicker. AJR Am J Roentgenol 198: W217-27, 2012.

106. Alongi F, Bolognesi A, Samanes Gajate AM, Motta M Landoni C, Berardi G, Alongi P, Gianolli L and Di Muzio N: Inflammatory pseudotumor of mediastinum treated with tomotherapy and monitored with FDG-PET/CT: Case report and literature review. Tumori 96: 322-326, 2010.

107. Boyce AM, Florenzano P, de Castro LF, Collins MT, Adam MP, Ardinger HH, Pagon RA, Wallace SE, Bean LJH, Stephens K and Amemiya A (eds): Fibrous Dysplasia/McCune-Albright Syndrome. In: GeneReviews ${ }^{\circledR}$ [Internet]. University of Washington, Seattle, WA, 1993-2019.

108. Collins MT, KushnerH, Reynolds JC, Chebli C, Kelly MH, Gupta A, Brillante B, Leet AI, Riminucci M, Robey PG, et al: An instrument to measure skeletal burden and predict functional outcome in fibrous dysplasia of bone. J Bone Miner Res 20: 219-226, 2005.

109. Toba M, Hayashida K, Imakita S, Fukuchi K, Kume N, Shimotsu Y, Cho I, Ishida Y, Takamiya M and Kumita S: Increased bone mineral turnover without increased glucose utilization in sclerotic and hyperplastic change in fibrous dysplasia. Ann Nucl Med 12: 153-155, 1998

110. Shigesawa T, Sugawara Y, Shinohara I, Fujii T, Mochizuki T and Morishige I: Bone metastasis detected by FDG PET in a patient with breast cancer and fibrous dysplasia. Clin Nucl Med 30: 571-573, 2005

111. Stegger L, Juergens KU, Kliesch S, Wormanns D and Weckesser M: Unexpected finding of elevated glucose uptake in fibrous dysplasia mimicking malignancy: Contradicting metabolism and morphology in combined PET/CT. Eur Radiol 17: 1784-1786, 2007

112. Su MG, Tian R, Fan QP, Tian Y, Li FL, Li L, Kuang AR and Miller JH: Recognition of fibrous dysplasia of bone mimicking skeletal metastasis on ${ }^{18} \mathrm{~F}-\mathrm{FDG}$ PET/CT imaging. Skeletal Radiol 40: 295-302, 2011.

113. D'Souza MM, Jaimini A, Khurana A, Tripathi M, Sharma R, Mondal A and Srivastava M: Polyostotic fibrous dysplasia on F-18 FDG PET/CT imaging. Clin Nucl Med 34: 359-361, 2009.

114. Kim M, Kim HS, Kim JH, Jang JH, Chung KJ, Shin MK, Hwang HS, Kim BC and Jung SY: F-18 FDG PET-positive fibrous dysplasia in a patient with intestinal non-Hodgkin's lymphoma. Cancer Res Treat 41: 171-174, 2009.

115. Choi YY, Kim JY and Yang SO: PET/CT in benign and malignant musculoskeletal tumors and tumor-like conditions. Semin Musculoskelet Radiol 18: 133-148, 2014.
116. Kamaleshwaran KK, Joseph J, Kalarikal R and Shinto AS: Image Findings of Polyostotic Fibrous Dysplasia Mimicking Metastasis in F-18 FDG Positron Emission Tomography/Computed Tomography. Indian J Nucl Med 32: 137-139, 2017.

117. Ruggieri P, Sim FH, Bond JR and Unni KK: Malignancies in fibrous dysplasia. Cancer 73: 1411-1424, 1994.

118. Wei WJ, Sun ZK, Shen CT, Zhang XY, Tang J, Song HJ, Qiu ZL and Luo QY: Value of ${ }^{99 \mathrm{~m} T c-M D P}$ SPECT/CT and ${ }^{18} \mathrm{~F}-\mathrm{FDG}$ PET/CT scanning in the evaluation of malignantly transformed fibrous dysplasia. Am J Nucl Med Mol Imaging 7: 92-104, 2017.

119. Chen CC, Czerwiec FS and Feuillan PP: Visualization of fibrous dysplasia during somatostatin receptor scintigraphy. J Nucl Med 39: 238-240, 1998.

120. Papadakis GZ, Manikis GC, Karantanas AH, Florenzano P, Bagci U, Marias K, Collins MT and Boyce AM: ${ }^{18} \mathrm{~F}-\mathrm{NaF}$ PET/CT imaging in fibrous dysplasia of bone. J Bone Miner Res 34: 1619-1631, 2019.

121. Papadakis G, Manikis G, Karantanas A, Marias K, Bagci U, Florenzano P, Collins M and Boyce A: Fibrous dysplasia related ${ }^{18} \mathrm{~F}-\mathrm{NaF}$ activity in the spine is significantly higher in patients with scoliosis, compared to patients without spinal deformity. J Nucl Med 60 (Suppl 1): 1298S-1298S, 2019.

122. Papadakis G, Manikis G, Karantanas A, Marias K, Bagci U, Florenzano P, Collins M and Boyce A: Positive Association between Fibrous Dysplasia (FD) related ${ }^{18} \mathrm{~F}-\mathrm{NaF}$ activity and Bone Turnover Markers (BTMs). J Nucl Med 60 (Suppl 1): 90S-90S, 2019.

123. Papadakis G, Manikis G, Karantanas A, Marias K, Collins M and Boyce A: Application of ${ }^{18} \mathrm{~F}-\mathrm{NaF}$ PET/CT imaging in prognosis of fractures and treatment planning in patients with fibrous dysplasia. J Nucl Med 58 (Suppl 1): 308S-308S, 2017.

124. Papadakis GZ, Manikis GC, Karantanas AH, Marias K, Collins MT and Boyce AM: Application of ${ }^{18} \mathrm{~F}-\mathrm{NaF}$ PET/CT imaging in fibrous dysplasia. Horm Res Paediatr 88 (Suppl 1): 20-20, 2017.

125. Delso G, Fürst S, Jakoby B, Ladebeck R, Ganter C, Nekolla SG, Schwaiger $M$ and Ziegler SI: Performance measurements of the Siemens mMR integrated whole-body PET/MR scanner. J Nucl Med 52: 1914-1922, 2011

126. Levin CS, Maramraju SH, Khalighi MM, Deller TW, Delso G and Jansen F: Design features and mu-tual compatibility studies of the time-of-flight PET capable GE SIGNA PET/MR system. IEEE Trans Med Imaging 35: 1907-1914, 2016.

127. Partovi S, Kohan A, Rubbert C, Vercher-Conejero JL, Gaeta C, Yuh R, Zipp L, Herrmann KA, Robbin MR, Lee Z, et al: Clinical oncologic applications of PET/MRI: A new horizon. Am J Nucl Med Mol Imaging 4: 202-212, 2014

128. Varoquaux A, Rager O, Poncet A, Delattre BM, Ratib O, Becker CD, Dulguerov P, Dulguerov N, Zaidi H and Becker M: Detection and quantification of focal uptake in head and neck tumours: (18)F-FDG PET/MR versus PET/CT. Eur J Nucl Med Mol Imaging 41: 462-475, 2014.

129. Platzek I, Beuthien-Baumann B, Langner J, Popp M, Schramm G, Ordemann R, Laniado M, Kotzerke J and van den Hoff J: PET/MR for therapy response evaluation in malignant lymphoma: Initial experience. MAGMA 26: 49-55, 2013.

130. Papadakis GZ, Karantanas AH, Tsiknakis M, Tsatsakis A, Spandidos DA and Marias K: Deep learning opens new horizons in personalized medicine. Biomed Rep 10: 215-217, 2019.

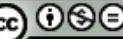

This work is licensed under a Creative Commons Attribution-NonCommercial-NoDerivatives 4.0 International (CC BY-NC-ND 4.0) License. 